

\section{CENTRO HISTÓRICO DE PUERTO LIMÓN, TRANSFORMACIONES SOCIALES QUE HAN CONTRIBUIDO A SU PATRIMONIALIZACIÓN}

Revista Trama

Volumen 8, número 1

Enero - Junio 2019

Páginas 107-149

ISSN: $1659-343 X$

http://revistas.tec.ac.cr/trama
Historic Center Of Limon Port, Cultural Transformations That Has Contributed To Its

Patrimonialization

Laura Chaverri-Flores ${ }^{1}$

Fecha de recepción: 31 de octubre de 2018 Fecha de aprobación: 12 de mayo de 2019

Chaverri-Flores, L. (2019). Centro Histórico de Puerto Limón, transformaciones sociales que han contribuido a su patrimonización. Trama, revista de ciencias sociales y humanidades, Volumen 8, (1), págs. 107-149.

DOI: https://doi.org/10.18845/tramarcsh.v8i1.4462
1. Profesora e investigadora. Universidad de Costa Rica, Escuela de Arquitectura y Escuela de Estudios Generales, Sede Rodrigo Facio. Instituto Tecnológico de Costa Rica, Escuela de Arquitectura y Urbanismo, Campus Tecnológico Local San José. Correo electrónico: laura.chaverri@ucr.ac.cr, lauchaverri@itcr.ac.cr 


\section{Resumen}

Este artículo se enfoca en un análisis de las transformaciones sociales y culturales que ha tenido el territorio del Centro Histórico de Puerto Limón, explorando los valores patrimoniales y simbólicos del mismo y reflexionando sobre el proceso de patrimonialización que ha tenido. Se analizan las razones por las cuales esta ciudad podría considerarse patrimonial, así como los procesos de su construcción social y discursiva. Además, se investiga sobre su valor histórico, social y simbólico, estético y paisajístico, y científico.

El área de estudio comprende treinta cuadras que presentan veinte de los veintiocho patrimonios declarados en toda la provincia. Sin embargo, en este caso es toda la ciudad la que se analiza como "objeto patrimonial", entendiendo patrimonio como un fenómeno, pues representa la significación simbólica que le da un grupo social a un objeto en diferentes temporalidades y no el objeto mismo.

Se utiliza el enfoque hermenéutico, es decir, una metodología de análisis basada en el arte de la interpretación a través de las épocas históricas con base en documentos como mapas, planos y fotografías. Se delimitan cuatro diferentes periodos de construcción social que se dividen de la siguiente manera: resistencias y autonomía frente al poder hegemónico español (1502-1852); la construcción formal de Puerto Limón y consolidación de una nueva cultura multiétnica que reprodujo prácticas que marginaron a la provincia de Limón del resto de "Costa Rica" (1852-1938); la "apertura" de Puerto Limón y las luchas sociales (1938-1970) y; por último, se define un periodo de contradicciones, retos y de exaltación y distorsión de la multiculturalidad (1970-2019).

Palabras clave: arquitectura, conservación, centro histórico, patrimonio cultural, patrimonio arquitectónico.

\section{Abstract}

This article focuses on the analysis of social and cultural transformations in the Historic Center of Limon Port by exploring the heritage process it has experienced. The reasons why this city could be considered heritage are analyzed, as well as the related process of social and ideation construction. Also, research includes its historic, social, symbolic, aesthetic, landscape and scientific value.

The study area encompasses thirty blocks that incorporate twenty of the twenty-eight declared patrimony sites of the province. However, in this case the entire city is analyzed as a "patrimony object", where patrimony is understood as a phenomenon since it represents the symbolic meaning that a social group gives to an object in different time frames, and to the object itself.

The methodology was based on a hermeneutic approach considering historical periods of time defined by documentation such as maps, plans and photographs. Four different social construction of the territory periods were divided as follows: resistances and autonomy against the Spanish hegemonic power (1502-1853); the official construction of Port Limon and consolidation of a new multiethnic culture at the margins of "Costa Rica" (1852-1938); the opening of Port Limon and its social struggles (1938-1970); and finally a period of contradictions and challenges is defined: the exaltation and distortion of multiculturalism (19702019).

Keywords: : architecture, conservation, historic center, cultural heritage, architectural heritage. 


\section{INTRODUCCIÓN}

A lo largo de la historia, el centro histórico de Puerto Limón ha estado influenciado por los intercambios tanto culturales como comerciales, debido a su relación con el Mar Caribe. Sin embargo, la importante presencia de grupos indígenas, así como las adversidades climáticas y topográficas, obstaculizaron el dominio español en la época colonial. No fue hasta el siglo XIX que, por razones políticas, económicas y su posición estratégica, el centro histórico de Puerto Limón se fue consolidando como un núcleo urbano, desarrollándose más que otras zonas de la provincia y aportando nuevos pobladores de diversos orígenes étnicos, predominando los afrodescendientes provenientes de Jamaica. Sin embargo, en el siglo XIX, la construcción de la identidad costarricense fue fundada sobre discursos políticos basados en la homogeneidad étnica, a partir de un ideal de blancura y descendencia europea, negando nuestra multiculturalidad. Si concebimos los territorios como construcciones socio-históricas, la provincia de Limón, a pesar de su posición privilegiada estuvo por mucho tiempo aislada del imaginario nacional.

Este territorio representado como espacio periférico y marginal se construyó gracias a la creación de un imaginario geográfico, hilado desde las élites de poder, que tiene como corolario la invención de un "Valle Central", que representa un espacio donde se localiza la "civilización" y la cultura, entre otras cosas, destinado a llevar sus lógicas a esos territorios "subordinados" (Gutiérrez, Jiménez, Martínez, 2013, p.230).

Dicho imaginario "valle-centralista" ha alimentado la exclusión de algunos territorios como fue el caso de la provincia de Limón. No obstante, el fenómeno de invisibilización del territorio limonense permitió que la población desarrollase una serie de tradiciones patrimoniales, validando su multietnicidad. En estos espacios sociales se han venido construyendo, a través de la historia, patrimonios culturales intangibles, en este caso bienes no materiales, como el inglés criollo limonense, las comidas tradicionales caribeñas, los cuentos de Anancy y el carnaval de Limón que todavía hoy nutren las dinámicas sociales de la ciudad; además, se ha desarrollado un ordenamiento territorial 
determinado por el ferrocarril y una arquitectura particular con rasgos caribeños con una gran adaptación al medio.

Este artículo se enfocará en un análisis de las transformaciones sociales y culturales que ha tenido el territorio del Centro Histórico de Puerto Limón, explorando los valores patrimoniales y simbólicos del mismoy reflexionando sobre el proceso de patrimonialización. A partir de la declaratoria y el análisis de ciertos bienes patrimoniales tanto tangibles como intangibles, procuraremos respondernos las siguientes preguntas: ¿cuál ha sido la evolución de la ciudad y de sus bienes patrimoniales a través del tiempo y cómo ha variado su significación según las ideologías del momento? ¿Se puede considerar el Centro histórico de Puerto Limón una ciudad patrimonial?

\section{REFERENTE TEÓRICO}

"El Patrimonio Cultural comprende los bienes culturales que en el proceso de desarrollo histórico, una sociedad hace suyos, ya sea porque los creó (elementos culturales autóctonos) o porque los hizo suyos, mediante la adopción o apropiación de significados" (Chang, 2004, p. 20). De esta forma, para esta antropóloga, los bienes patrimoniales que se olvidaron, se tornan parte de la memoria de algunos; mientras que los que continúan vigentes, pueden mantener su sentido original u otorgársele otro significado.

En los últimos años el concepto de patrimonio cultural ha evolucionado, y aunque existen algunas discrepancias según diferentes áreas de estudio, se ha reconocido como una construcción social (Prats, 1998; Drouin, 2005; Davallon, 2006; Dormaels, 2011). Para el antropólogo, Llorenç Prats (1998), las concepciones de invención y construcción social no pueden estar 
desligadas (p.63). Es decir, no se puede gestar una construcción social sin un discurso previo inventado y por otro lado, las invenciones necesitan de una construcción social para su aceptación colectiva. Un bien puede considerarse "patrimonial", sin necesidad de que haya sido declarado oficialmente. Se han dado casos en donde un bien ha sido patrimonializado oficialmente pero su pueblo no se ha apropiado del mismo; y por el contrario, bienes valorados por especialistas de la oficialidad pero desconocidos por la población. Para Dormaels (2011), el patrimonio se puede considerar como un fenómeno pues representa la significación simbólica que le da un grupo social a un objeto y no el objeto mismo.

Dormaels (2011) define la patrimonialización como "la constitución de la significación simbólica del objeto patrimonial" (p. 9-10). Los procesos de patrimonialización "se presentan como mecanismos que permiten legitimar la selección y jerarquización de ciertos elementos y lugares vinculados a determinados valores que dichos sectores desean mantener para asegurar su preservación" (PérezWinter, 2017, p. 197). Esasícomola patrimonialización depende de grupos sociales que le dan significado al objeto, según sus ideales y aspiraciones en momentos determinados. Su concepción puede ser hasta contradictoria ya que muchas veces se lleva a cabo bajo la argumentación de su protección, pero este proceso puede generar transformaciones que producen la pérdida de lo patrimonializado en un inicio.

La ciudad puede convertirse en "el objeto patrimonial" y se deben descifrar las diversas capas creadas por las diferentes significaciones que pudo llevar la conformación de la misma. Para García Canclini (1996), la ciudad puede funcionar como un palimpsesto, en donde se escriben historias superpuestas en otras creando imaginarios urbanos. En este sentido, el centro histórico de Limón puede ser visto como un collage de parches de diversos periodos. Como por ejemplo el antiguo cine Acón, que alguna vez fue cine, pero hoy alberga una tienda. Sin embargo, su nombre (que aún no ha sido cambiado), todavía nos recuerda su uso original. 


\section{METODOLOGÍA Y ÁREA DE ESTUDIO}

A pesar de que aún no ha sido declarado patrimonio oficialmente, como conjunto urbano, ya algunas instituciones como el Consejo Internacional de Monumentos y Sitios (ICOMOS) y la dirección de Patrimonio del Ministerio de Cultura y Juventud de Costa Rica han delimitado el Centro Histórico $(\mathrm{CH})$ y han venido desarrollando proyectos para fomentar su patrimonialización desde 1985. La delimitación del Casco histórico hecha por estas instituciones incluye toda la trama urbana conformada en 1929 (figura 1).

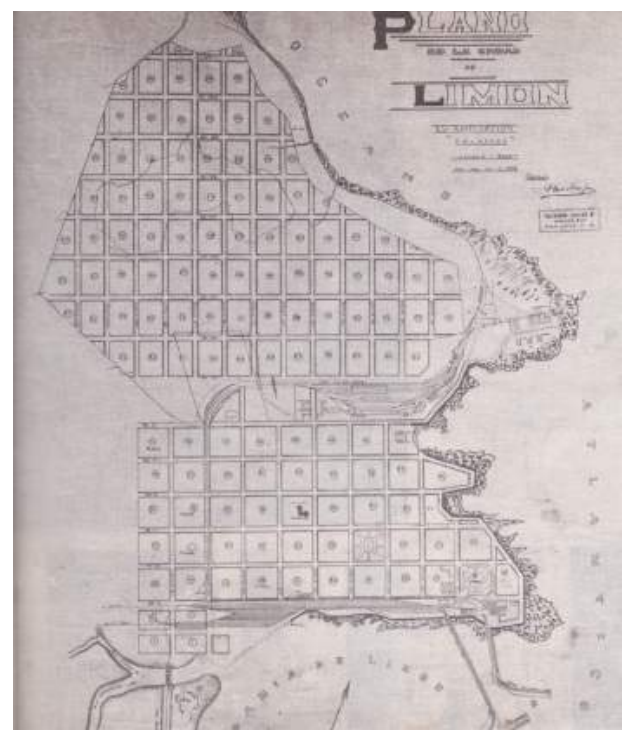

Figura 1. Plano proyectado en 1929 para la ciudad de Limón. Gutiérrez, S. (1991). Arquitectura Caribeña. p.29.

En este estudio, solo nos limitaremos al área expuesta en la figura 2, delimitada por la Avenida 7 al norte, la calle 7 al oeste y el mar Caribe al sur y al este, que contiene veinte bienes de interés histórico arquitectónico o urbanístico declarados por el Centro de Investigación y Conservación del Patrimonio Cultural (CICPC) del Ministerio de Cultura y Juventud de Costa Rica, así como dos inmuebles no declarados pero de importancia arquitectónica. A pesar de no estar circunscrita en el área antes expuesta, se tomará en cuenta la Isla Quiribrí ya que es fuertemente percibida desde 
la zona de estudio y la Antigua Línea Férrea entre Limón y Toro Amarillo, que comienza en la Ciudad analizada y se extiende hasta Guápiles. Además, en el desarrollo del trabajo, en algunos casos, se ampliarán los límites antes planteados para comprender la escala regional y la relación de la zona de estudio con la provincia de Limón y el país en general.

Para esta investigación del patrimonio urbano, se utilizó una metodología de análisis basada en la interpretación a través de las épocas históricas. Se reconstruyeron los procesos que llevaron a la forma y al significado con base en documentos como mapas, planos, arte popular y fotografías. Desde el estudio de diferentes textos de historia, historia de la arquitectura, patrimonio cultural e investigaciones del CICPC del área de estudio y trabajo de campo se definieron diferentes etapas, marcadas por el cambio de actores e importantes acontecimientos históricos que generaron transformaciones tanto espaciales como sociales en el espacio estudiado. De esta forma, con base al referente teórico sobre la patrimonialización, se estudiaron los diferentes significados del $\mathrm{CH}$ de Limón, como de ciertas edificaciones y tradiciones patrimonializadas. Se analizaron diferentes imágenes para lograr comparar cambios espaciales de la ciudad basados en ideologías de diferentes momentos históricos.

\section{BIENES CULTURALES TANGIBLES EN EL CENTRO HISTÓRICO}

EL Centro Histórico de Limón tiene las características expuestas por la UNESCO (2011) que lo definirían como Centro Histórico Urbano, es decir:

\footnotetext{
Conjunto formado por las construcciones, espacios públicos y privados, calles, plazas y las particularidades geográficas o topográficas que lo conforman y ambientan y que en determinado momento histórico tuvo una clara fisonomía unitaria, expresión de una comunidad social, individualizada y organizada (UNESCO, 2011).
} 
Veinte de los veintiocho bienes declarados para toda la provincia, se ubican en un área de treinta cuadras o $0.3 \mathrm{~km}^{2}$ en contraste con los $1765.79 \mathrm{~km}^{2}$ que posee el Cantón y los 9179.23 $\mathrm{km}^{2}$ de extensión que posee toda la provincia de Limón. En otras palabras, el $71 \%$ de los bienes declarados oficialmente en la provincia, se ubican en solo el $0.003 \%$ del territorio. Es por esto que podemos afirmar que desde la oficialidad, la zona en cuestión es la que ha sido mejor valorada en toda la provincia.

En el mapa del área de estudio (figura 2) es posible observar la relación y cercanía entre las diferentes edificaciones con interés patrimonial, así como los ejes peatonales y el recorrido del Carnaval que atraviesa dichas edificaciones (Ramírez, 2008). El mapa tiene una importante relación con la tabla, ordenada según las relaciones espaciales y un posible recorrido de la ciudad. Esta última resume la época constructiva de cada bien patrimonial, su estado y fecha de declaratoria, su clasificación y finalmente el profesional o institución a cargo del diseño o construcción. Los bienes se dividieron según la clasificación del CICPC en: plaza, parque, construcción, baldío, ruinas, otro o todo.

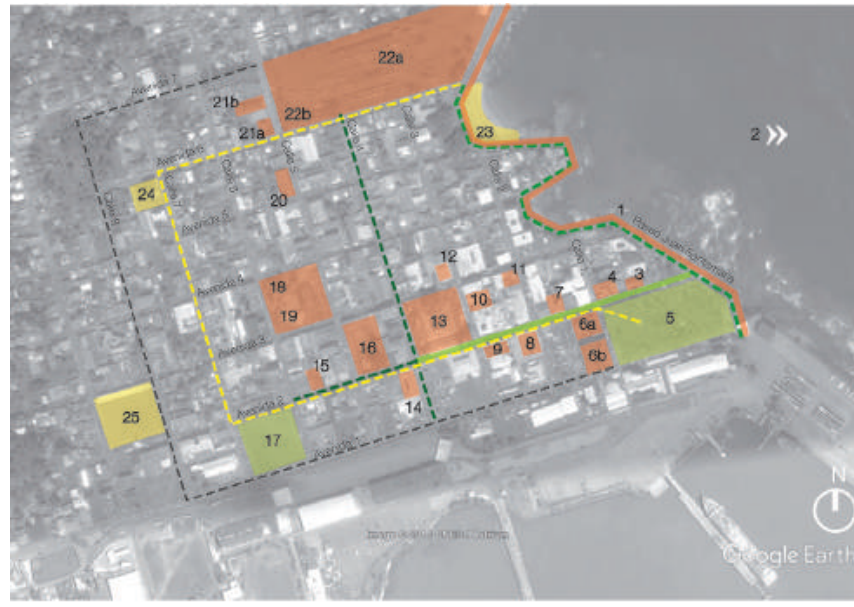

Stios con valor patrimcnial $\square$ Sitios de referencia $\square$ Parquas y áreas deportivas con valor petrimorial

Figura 2. Sitios de valor patrimonial en el Centro Histórico de la provincia de Limón.

Fuente: Elaboración propia con base en foto aérea de Google Earth (2016).

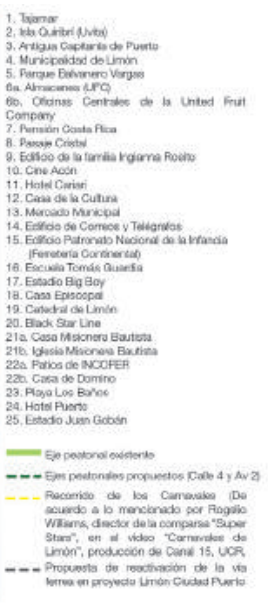

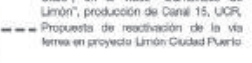




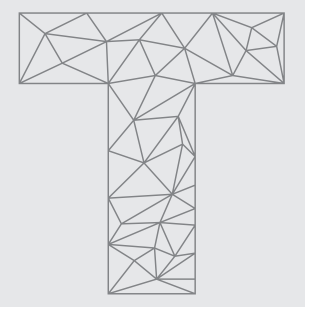

Laura Chaverri Flores

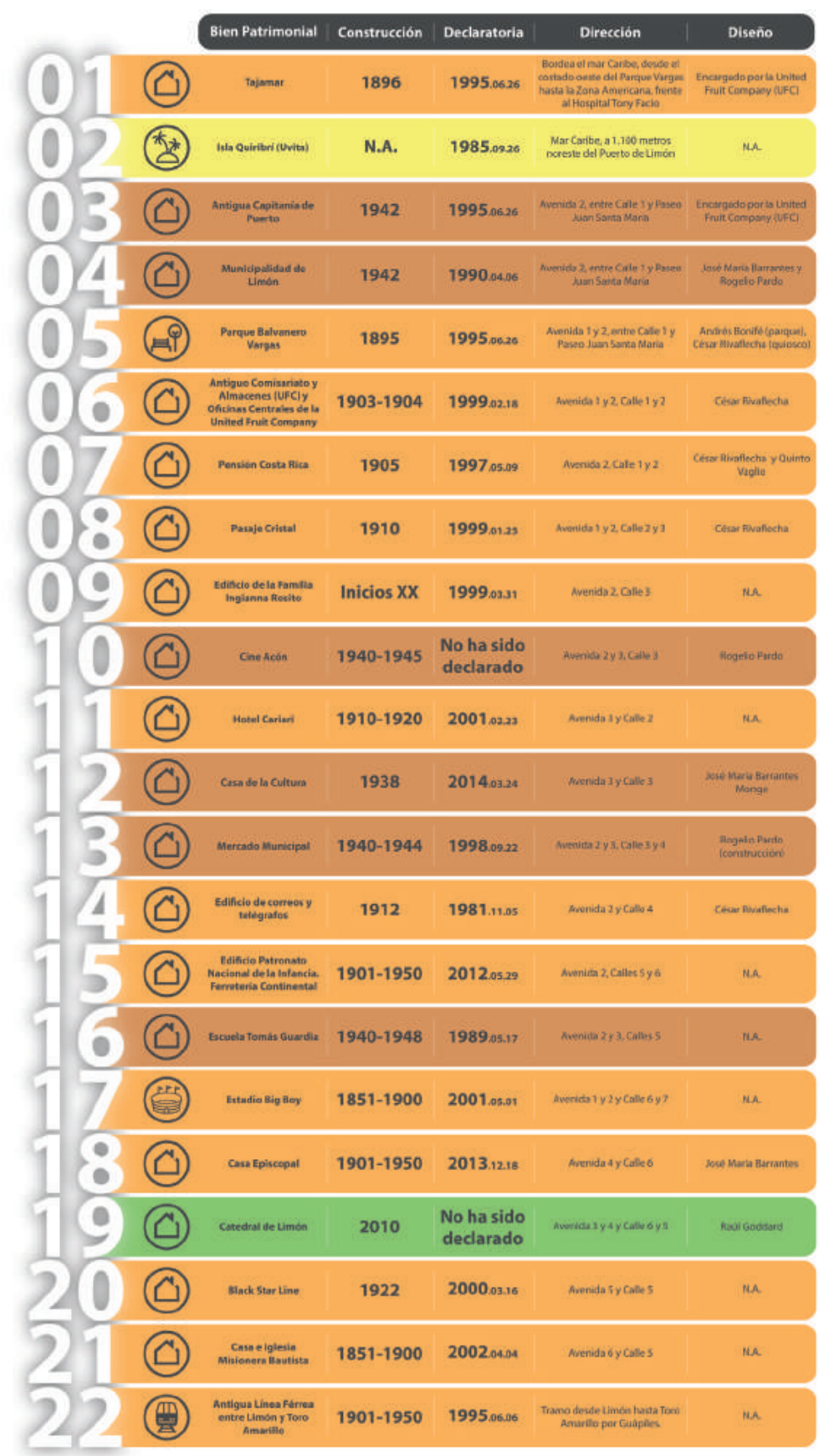

\begin{tabular}{|c|c|}
\hline SIMBOLOGIA & Nerioder de patrimonialitasión \\
\hline Comsificación de los biones & 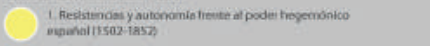 \\
\hline (4) contrucoon (7) Esadio & 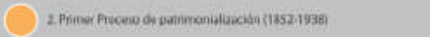 \\
\hline (98) Uneatirocarit & 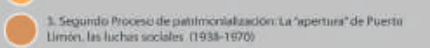 \\
\hline (Ai) pren & 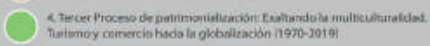 \\
\hline
\end{tabular}

Tabla 1. Bienes de interés arquitectónico o urbanístico. Fuente: Elaboración propia. Basada en CICPC 
Muchas veces, concebimos los bienes patrimoniales que conforman la ciudad de forma aislada; no obstante, son las relaciones y el espacio urbano entre los mismos, los que provocan un sentido de pertenencia y le dan una significación social. El parque Vargas, que abarca todo un cuadrante, posee en tres costados seis bienes patrimoniales declarados con diferentes significados y; la relación del parque con tales bienes es lo que fortalece esta imagen de conjunto histórico. Por ejemplo, desde dicho parque se perciben fugas visuales hacia el Tajamar (figura 3 ) y la isla Quiribrí.

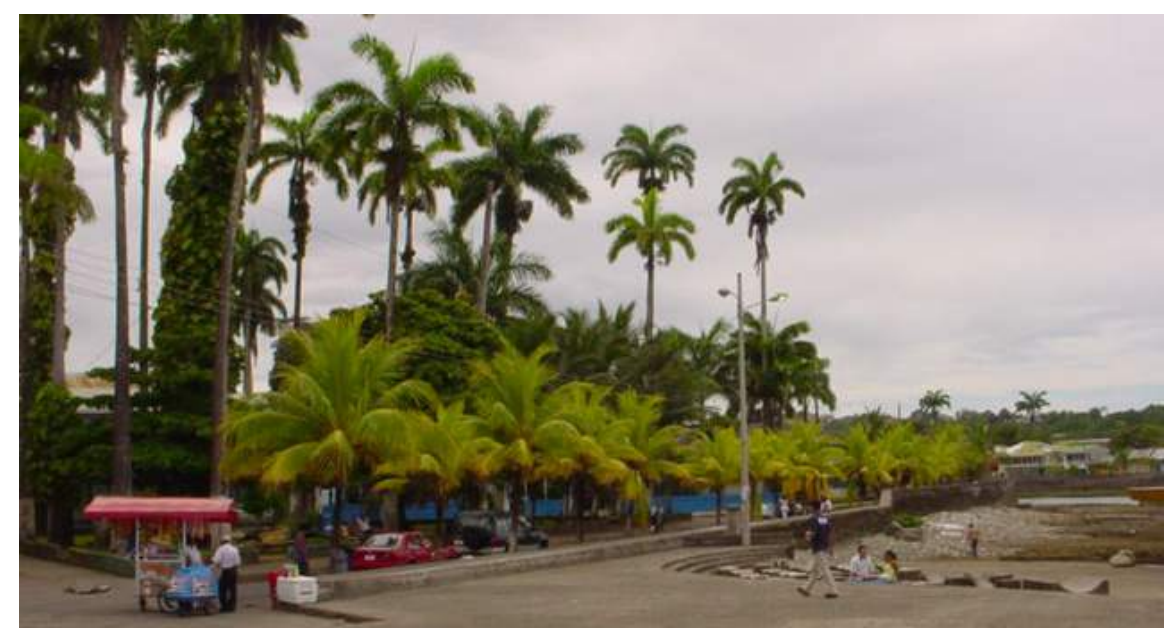

Figura 3. Vista del Tajamar, situado en la ciudad de Limón.

Fuente: Elaboración propia con base en el trabajo de campo (2002).

Según Dormaels (2011)"para pasar de la ciudad al patrimonio, se agrega un elemento social y performativo" (p.11). No es suficiente solo estudiar la evolución formal de lo construido desde el punto de vista tangible, sino es también importante comprender las representaciones de la ciudad desde los imaginarios, la literatura, el arte, la música, es decir lo intangible. De esta forma, la ciudad se va entendiendo como un escenario de relaciones urbanas, que necesitan de un tiempo y un espectador y no como de un objeto inerte. 


\section{ETAPAS DEL PROCESO DE TRANSFORMACIÓN SOCIAL Y PATRIMONIALIZACIÓN DEL CENTRO HISTÓRICO DE LIMÓN}

1. Resistencias y autonomía frente al poder hegemónico español (1502-1852)

Si nos referimos a la construcción de un territorio y sus valores simbólicos, es muy difícil no relacionar la zona de estudio con "la Conquista de Costa Rica". La Isla Quiribrí fue la primera imagen que tuvo Cristóbal Colón de Costa Rica, en su último viaje en 1502 (Gutiérrez, 1991). Gracias a Colón se creó "el mito" que describía el territorio como un lugar lleno de oro y riquezas naturales y; se estableció por primera vez el contacto de los indígenas pococís y tariacas, que habitaban la zona, con los españoles, provocando importantes transformaciones sociales, económicas y culturales.

No es de extrañar entonces que esta isla haya sido uno de los primeros patrimonios culturales en ser declarados formalmente por el Centro de Patrimonio. El palimpsesto de la construcción social de dicha isla es fácil de apreciar con solo el hecho de su cambio de nombre con respecto al grupo social que le daba un valor (figura 4). Antes de la llegada de los españoles era conocida como Quiribrí por los indígenas. Colón la bautizó como La Huerta y posteriormente su nombre se reemplazó a Uvita. Finalmente, en 1986 la Comisión Nacional de Nomenclatura procede a recuperar el nombre original de Quiribrí en honor al primer pueblo que la "valorizó" (Zamora, 2012).

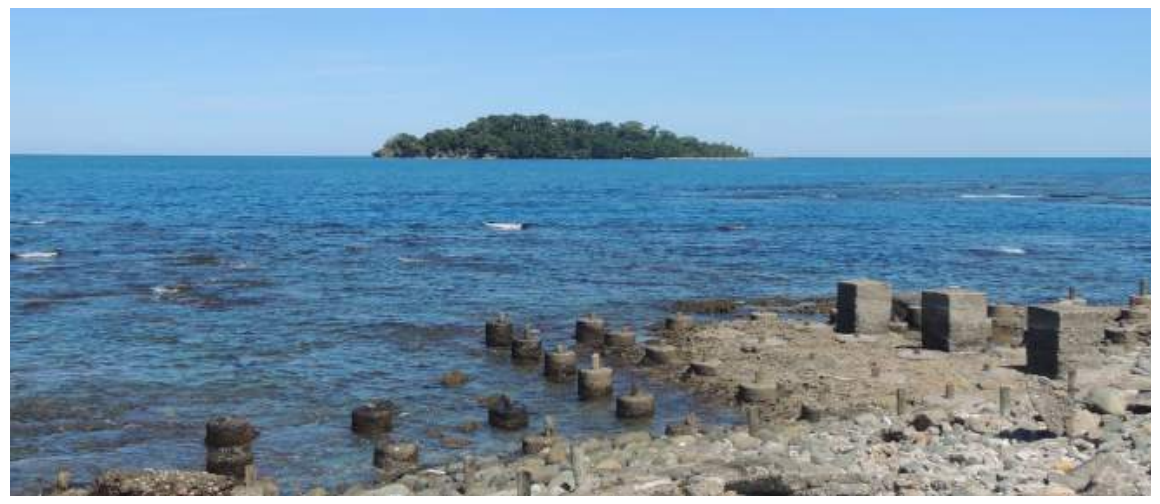

Figura 4. Vista al mar Caribe donde se aprecian capas de diferentes épocas, la isla Quiribrí y el Tajamar. Fuente: Elaboración propia con base en el trabajo de campo (07/10/2018). 
En las décadas de 1540 a 1560, los procesos de conquista del Caribe fueron infructuosos debido a la resistencia indígena y las dificultades tanto topográficas como climáticas, por lo que los conquistadores continuaron la invasión por el Pacífico, para lograr la conquista de la región central de "Costa Rica" en 1560 (Fonseca y Barascout, 1998, p. 85). De esta forma, en el periodo colonial, no fue posible la consolidación de centros urbanos en el Caribe y la presencia española fue escasa (Fonseca y Barascout, 1998, p. 85). En esta época funcionaron algunos puertos en muy malas condiciones en Suerre y Matina y se realizaron construcciones aisladas. El Fuerte San Fernando de Matina, por ejemplo, se construyó en 1742 para protegerse de los piratas y zambos mosquitos (Fonseca, Alvarenga y Solórzano, 2002).

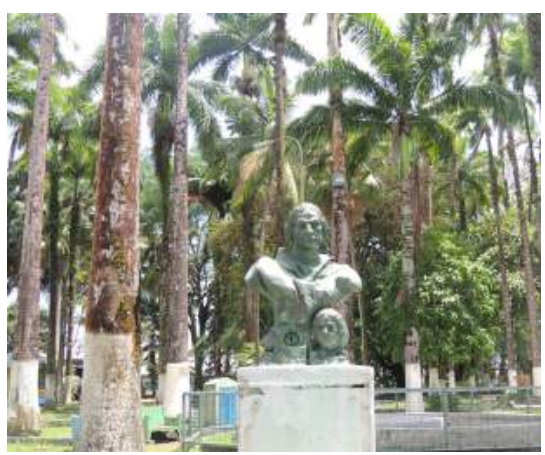

Figura 5. Busto de Cristóbal Colón y su hijo Hernando en el Parque Vargas de la ciudad de Limón. Elaboración propia con base en el trabajo de campo (14/05/2014).

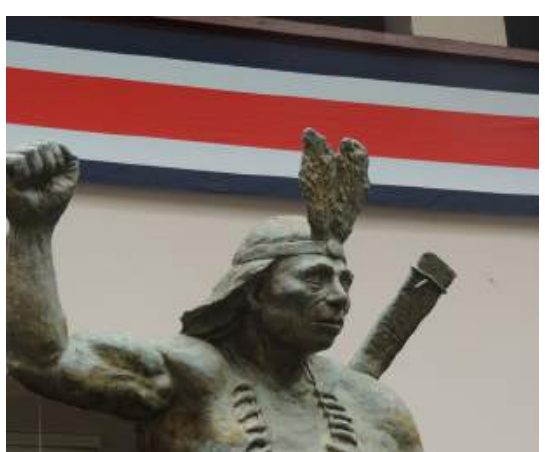

Figura 6. Busto de Pablo Presbere frente a la antigua municipalidad de la provincia de Limón. Elaboración propia con base en el trabajo de campo (22/09/2012).

Volviendo a nuestra zona de estudio concreta, en el Centro histórico, no se han documentado construcciones tangibles de este periodo histórico; no obstante, se han construido diferentes monumentos, bustos o esculturas como símbolos del mismo. En el parque Vargas por ejemplo, se encuentra el busto de bronce de Cristóbal Colón, construido en 1990 (figura 5). En contraposición con la escultura de Pablo Presbere en los jardines de la Municipalidad de Limón, junto al árbol de Limón, que afirma el discurso, le dio origen al nombre de la ciudad (figura 6). 
Pa-Bru fue cacique de Suinsi, y luchó por proteger su territorio, evitando que los españoles conquistaran Talamanca. Sin embargo, fue capturado por el ejército español y sentenciado a muerte en 1710. A pesar de que por mucho tiempo los españoles utilizaron su asesinato como símbolo de poder del imperio español, no fue hasta en 1996 que se declara a este personaje como defensor de la libertad de los pueblos originarios y se gestiona la construcción de un nuevo héroe nacional. Este hecho trastocó el imaginario del supuesto héroe nacional asociado al labriego y sencillo vallecentralista e incluyó al indígena que había estado excluido dentro de la conformación de la nación. Aunque Presbere fue ejecutado, hasta cierto punto sus esfuerzos y los de sus seguidores rindieron fruto, ya que a los españoles y cartaginenses se les imposibilitó tomar por la fuerza a Talamanca y tuvieron que aceptar su tácita autonomía (Ruz, 1991).

En el periodo analizado, el territorio tiene poco protagonismo de los grupos de poder español, en donde se dan diferentes luchas de poder y de apropiación de territorio, pero sin éxito. Además, se tiene poca documentación sobre la apropiación simbólica del territorio por parte de los indígenas, por lo que podríamos concluir que en este periodo no se llevó a cabo el proceso de patrimonialización de la región. Sin embargo, este representa una etapa histórica del palimpsesto, en donde las luchas sociales, imposibilitaron la hegemonía de la corona española consolidándose héroes indígenas muy poco recurrentes en el resto del país. No fue hasta 1852 con la construcción de Puerto Limón que toda la dinámica social del área de estudio se transformó radicalmente, así como sus actores en la conformación del territorio. 
2. La construcción formal de Puerto Limón, consolidación de una nueva cultura multiétnica al margen de "Costa Rica" (1852-1938)

El primer momento de construcción social del Centro Histórico de la Ciudad de Puerto Limón puede estar definido con la construcción tangible de la misma, asociada a la creación de la ruta del ferrocarril y la actividad bananera. En esta nueva construcción urbana y social los actores principales fueron el gobierno de Costa Rica, las empresas estadounidenses y la mano de obra extranjera, mayoritariamente jamaiquina. En 1852 el presidente Mora Porras decretó la construcción de Puerto de Limón para el intercambio de mercancías, siendo declarado como el puerto principal del país hasta 1865 (Sanou y Quesada, 1998; Gómez Vargas, 2010). De esta manera, comienza el proceso de ideación e invención de esta ciudad.

En 1871, Tomás Guardia realizó un contrato con Henry Meiggs que sería cedido a los hermanos Keith, para construir el ferrocarril en donde se les concedería por 99 años las tierras aledañas a la infraestructura del tren (Sanou y Quesada, 1998). En este mismo año, en el área que hoy conforma el casco histórico, solo habían dos casas, se construyeron un almacén y un comisariato, y se comenzaron las obras ferroviales (Gutiérrez, 1991). El ingeniero Miguel Velásquez realizó el primer trazado de calles ortogonales, creando una organización con forma de damero, en donde cada cuadrante se dividió en ocho lotes o solares (Gutiérrez, 1991; Gómez Vargas, 2010). 


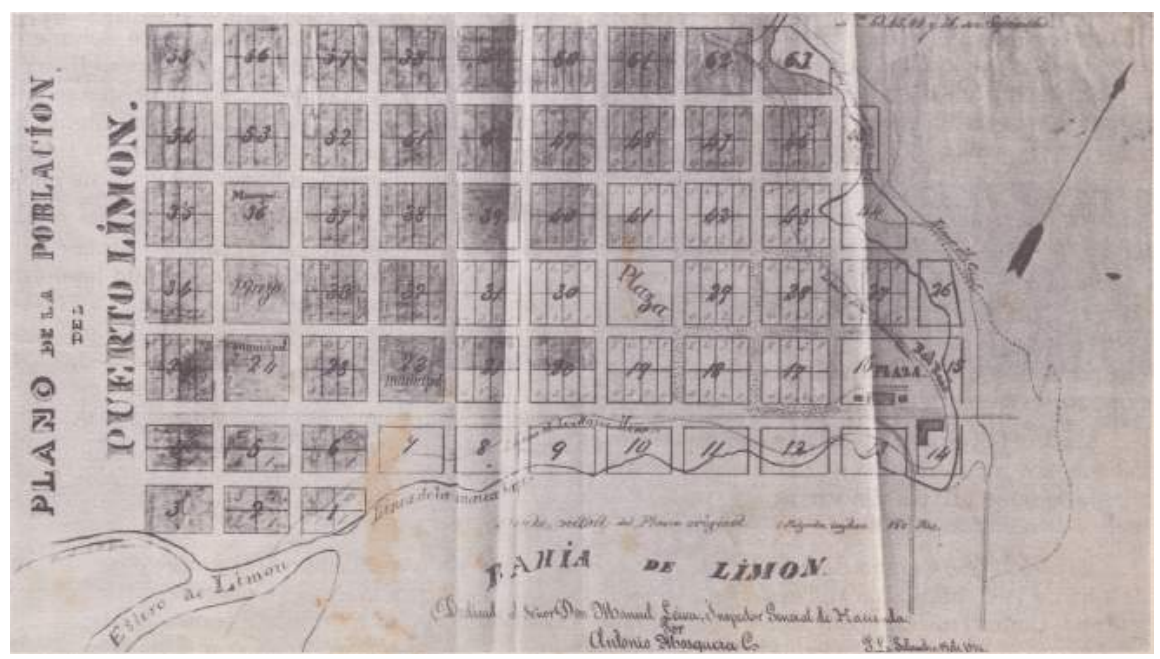

Figura 7. Plano de la población de Puerto Limón de 1874 (Citado por Gutiérrez, 1991. p.25).

Con la intención de densificar la población, se trasladó un caserío de Puerto Moín a Puerto Limón y en 1872 se establecieron estímulos como la donación de solares para construir un negocio o vivienda a los nuevos pobladores. No obstante, si al cabo de dos años los habitantes no generaban una construcción, se expropiaban con multa (Gutiérrez, 1991; López, 1984). En el plano de 1874 (figura 7), se observa esta organización, en donde se concibieron 63 cuadrantes de los cuales la mayoría estaban divididos en ocho lotes, pero otros se pensaron para potenciar el espacio público y la vida social: tres cuadrantes fueron concebidos como plazas y tres de uso municipal. Uno de estos tres últimos, fue ocupado por el Estadio de béisbol Big Boy, inaugurado en 1887 y convirtiéndose en un importante espacio recreativo con gran valor afectivo y social (figura 8 y 9 ). 


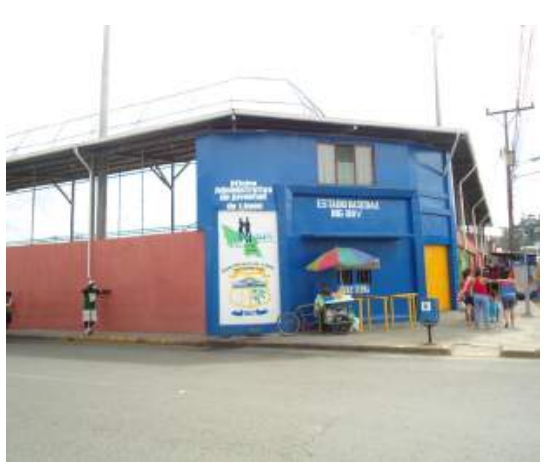

Figura 8. Vista del acceso principal del Estadio Big Boy posterior a la intervención de su fachada. Fuente: Elaboración propia con base en el trabajo de campo $(11 / 10 / 2011)$.

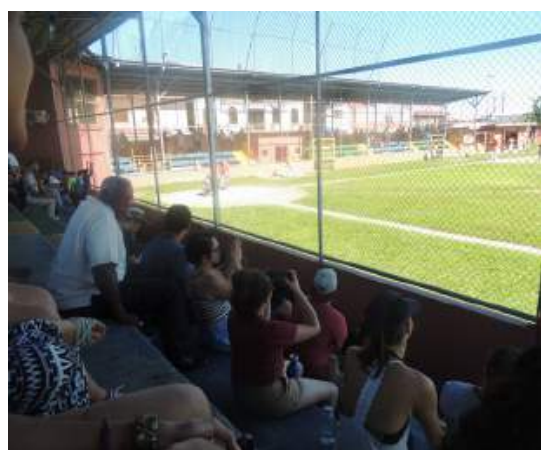

Figura 9. Espectadores en Estadio de Big Boy. Fuente: Fuente: Elaboración propia con base en el trabajo de campo (07/10/2018).

En la figura 10, se observa la organización del cuadrante dividido en donde solo podía haber una construcción por lote. Esta agrupación potenció el nacimiento de "Ios patios limonenses", que representaron espacios urbanos de gran valor social donde se desarrollaban actividades como el juego y las pilas vecinales. En 1876, Puerto Limón se convirtió en un pueblo organizado con 1200 habitantes y 500 casas de habitación y ya en 1882, se transformó en un centro comercial con gran cantidad de infraestructura (Gutiérrez, 1991).
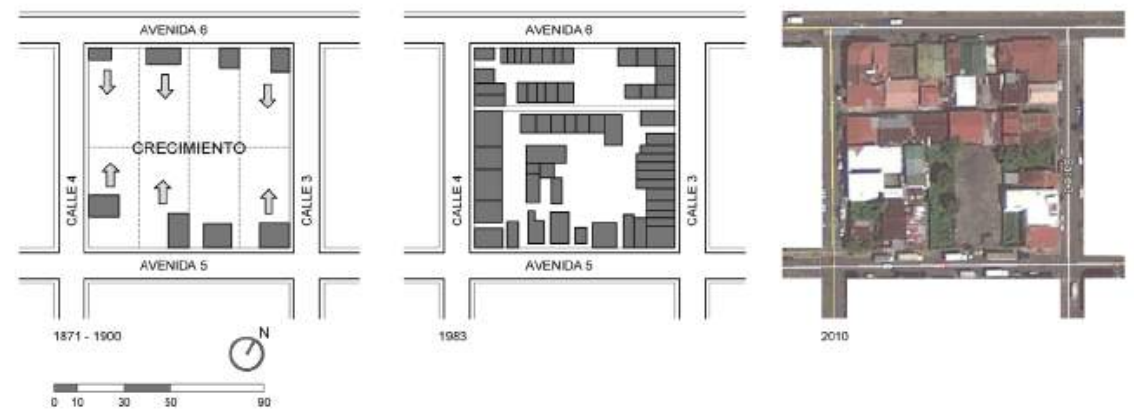

Figura 10. Retícula de asentamiento original (periodo de 1871-1900, 1983 y 2010).

Fuente: Elaboración propia con base en López Garat (1984) y vista aérea de Google Earth (2016). 
El Tajamar, construido en 1896, representa un elemento imprescindible y simbólico en el contexto urbano de la Ciudad, pues además de contener la subida de la mareas que alcanzaba el actual Mercado (Gómez Vargas, 2010), fomentó la vida urbana a lo largo del Mar Caribe, propiciando espacios de ocio y de esparcimiento. Constituye un muro de piedra de $50 \mathrm{~cm}$ de espesor, que se posa en forma ondulada en el borde del mar. Además, el tajamar cuenta con un pretil más bajo que mira hacia la ciudad, y que es utilizado para sentarse o ponerse de pie sobre él y observar el océano y la ciudad (figura 11 y 12).

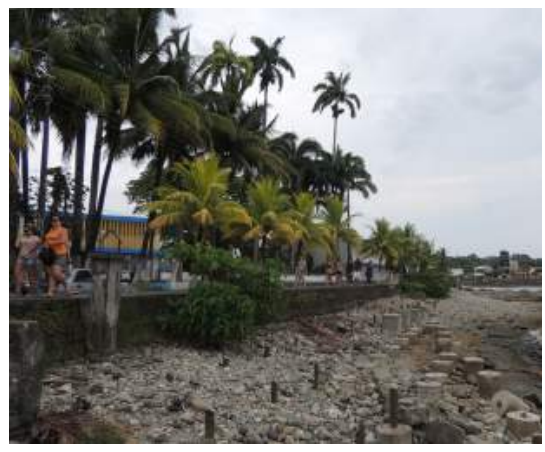

Figura 11. Tajamar, Limón. Luego del terremoto de 1991, se da un retiro del mar que se aprecia en la fotografía.

Fuente: Elaboración propia con base en el trabajo de campo (28/02/2012).

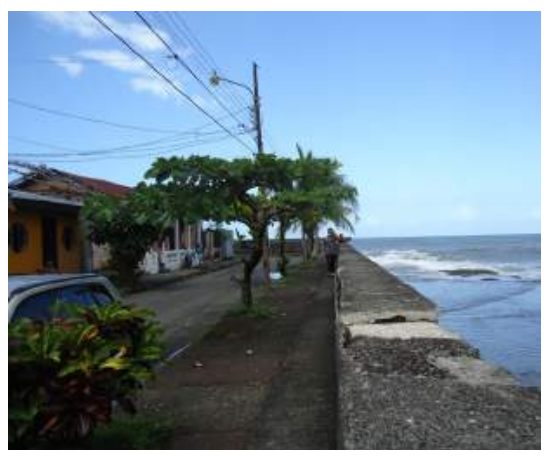

Figura 12. Tajamar, Limón.

Fuente: Elaboración propia con base en el trabajo de campo (22/09/2011).

El Parque Balvanero Vargas se construyó en 1895 como parte de la trama urbana, en un sitio estratégico en cuanto a visuales frente al Tajamar. Fue bautizado con el nombre del gobernador y diseñado por el jardinero francés Andrés Bonifé (Sanou, 2010). Su trazado es neoclásico, presentando un quiosco en el centro y cuatro ejes de circulación, dos ortogonales y dos diagonales. Parte de su diseño original aún se conserva con las palmas reales colocadas en línea, palmas múltiples y árboles de laurel de la india. 


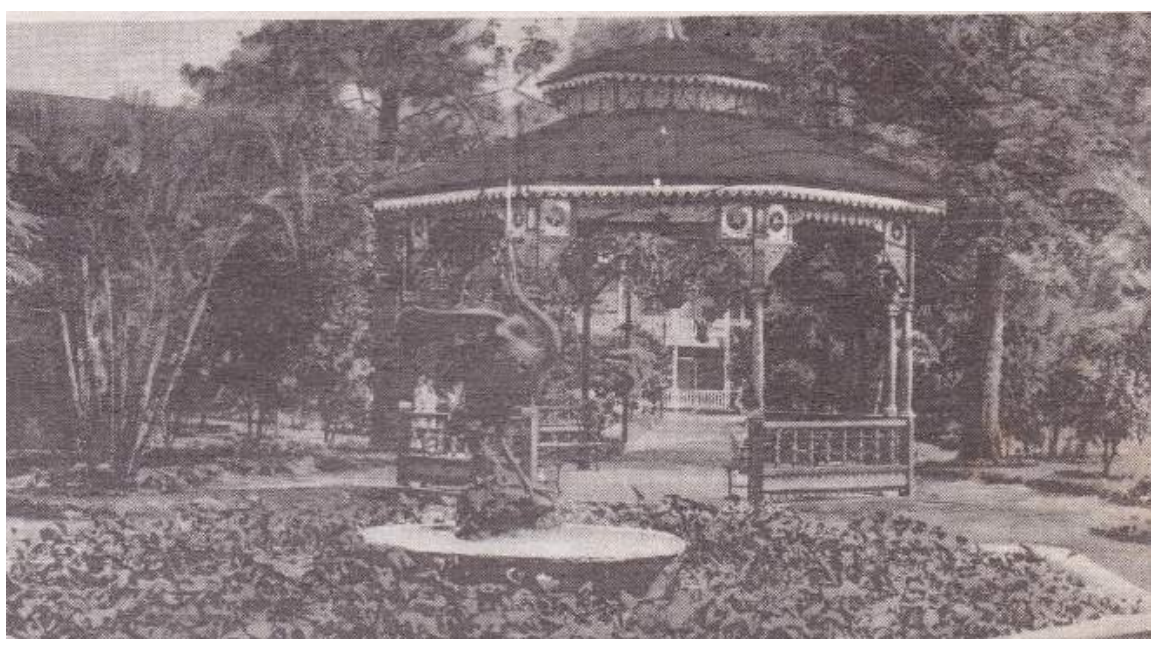

Figura 13. Fotografía del Parque Vargas en 1910 (Gutiérrez, S.,1991, p.29).

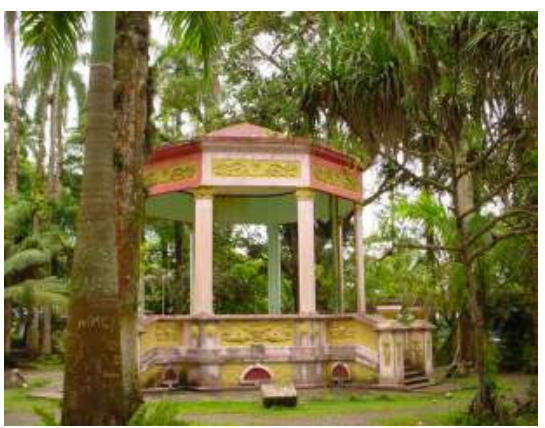

Figura 14. Parque Balvanero Vargas.

Fuente: Elaboración propia con base en el trabajo de campo (2002).

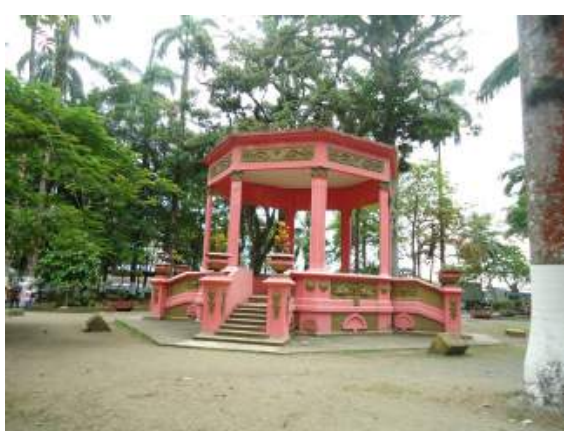

Figura 15. Parque Balvanero Vargas.

Fuente: Elaboración propia con base en el trabajo de campo (28/02/2011).

El parque ha sufrido diversas transformaciones, por ejemplo, el primer quiosco era prefabricado, de estilo victoriano y el techo de forma octagonal (Sanou, 2010). En la figura 13 se muestra una postal de 1910, exponiendo este quiosco, mientras que las figuras 14 y 15 presentan el mismo espacio pero en el 2002 y el 2011, exponiendo el quiosco ecléctico con influencia neoclásica y art nouveau diseñado por César Rivaflecha, que reemplazó al primero de 1910. En esta misma fecha, se construyeron asientos de mampostería y el alumbrado, con focos de luz de arco, motivando 
espacios para actividades opcionales. Este ha sido el sitio de reunión, socialización y de encuentro de la ciudad convirtiéndose en un nodo e hito urbano.

La población de la época se apropió fácilmente de este "objeto" que adquirió un significado social, simbólico y cultural pues se dice que era considerado como uno de los parques más bellos de Centroamérica generando así un enorme sentido de apropiación. Esta concepción de belleza coincide con los ideales del periodo valorando la vegetación foránea y la arquitectura con influencia europea.

En 1902, Limón pasa a ser provincia. Para 1915 existieron alrededor de cuatrocientos cincuenta establecimientos comerciales en donde la gran mayoría eran propietarios extranjeros, aportando en 1908 los ingresos fiscales más altos sobre las otras provincias de Costa Rica (Gutiérrez, 1991). Es así como en 1927 vivían 2.2 extranjeros por cada costarricense en la provincia de Limón (Viales, 1998; Meléndez, 2005). Con relación al lugar de nacimiento en $1927,52,2 \%$ de los habitantes de la provincia nacieron en CR (incluyendo extranjeros ya que los hijos de extranjeros no obtenían nacionalidad por nacimiento), $28.2 \%$ en Jamaica, $5.3 \%$ en otros países del Caribe, $9 \%$ en Nicaragua y $4.5 \%$ en otros países (Viales, 1998).

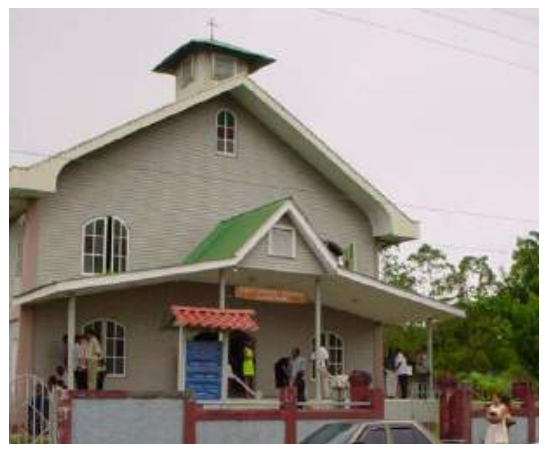

Figura 16. Iglesia Bautista.

Fuente: Elaboración propia con base en el trabajo de campo (2002).

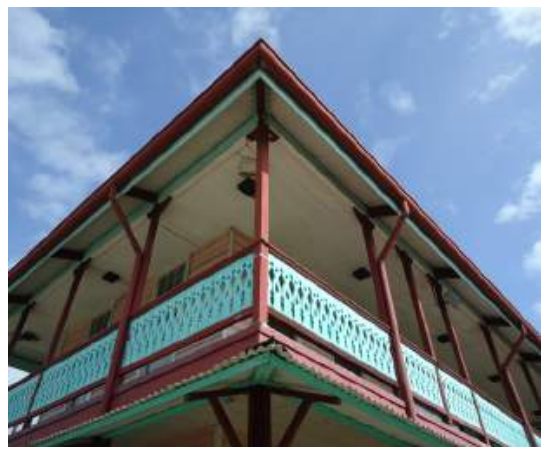

Figura 17. Casa Misionera Bautista.

Fuente: Elaboración propia con base en el trabajo de campo (28/02/2011). 
Como hemos constatado, este periodo tuvo un importante valor científico con la creación del primer instrumento de ordenamiento público, que rompió con el modelo de ciudad colonial que presentaban las otras cabeceras de provincia. En el plano de la ciudad de 1929 (figura 1) se muestra la evolución con respecto al plano de 1874 (figura 7). En el perímetro se ubicaron el Tajamar y los muelles; y se consolidaron los arrecifes. Se encuentran trazados el parque Vargas, y con una geometría muy similar a solo dos cuadras, otro parque, cuadrante que hoy ocupa el Mercado. Para esa época Puerto Limón contaba con dos muelles, una gobernación, comandancia, cárcel y hospital. En cuanto a la arquitectura religiosa, se desarrolló un importante mosaico de edificaciones que incluía diferentes tipos de cultos como logias masónicas, templos protestantes e iglesia católica. En 1871 se construyó la Iglesia Bautista siguiendo el modelo del revival gótico del Alto Victoriano (Sanou, 2010; figura 16). La Casa Misionera Bautista fue una de las primeras casas de madera de dos plantas construidas en el Centro Histórico y representa las características básicas de la arquitectura caribeña (figura 17). Este conjunto religioso constituye todavía hoy, un testimonio de la arquitectura del siglo XIX.

También se encuentran en pie y son patrimonios declarados: el Antiguo Comisariato y Almacenes de la United Fruit Company (1903 a 1904), Pensión Costa Rica (1905), Pasaje Cristal (1910) y el Edificio de Correos y Telégrafos (1912) construidos por César Rivaflecha (CICPC). Los dos primeros, al frente del Parque Vargas, demuestran el poderío de la United Fruit Company y conformaban junto a la estación, demolida en 1990, el corazón de la ciudad (fig.18, 19,20 y 21). En la figura 18, se muestra una interpretación artística de la época. En donde se aprecia la armonía cromática entre los edificios y las vestimentas de los pobladores predominantemente negros. De esta forma, estos edificios conformaban un conjunto urbano determinado por la línea del ferrocarril, símbolo de progreso. Se observan mujeres, niños y hombres apropiándose del espacio público, realizando actividades cotidianas, comerciales y de 
sociabilización. Esta interpretación contrasta con la fotografía de Manuel Gómez Miralles de 1927, del mismo espacio que cuenta con una mayoría de personajes masculinos.

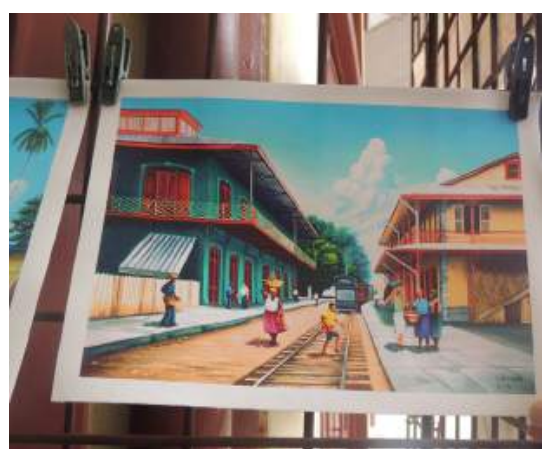

Figura 18. Pintura que muestra Antiguas Oficinas de la UFC y Estación de Ferrocarril.

Fuente: Elaboración propia con base en el trabajo de campo (17/10/2015).

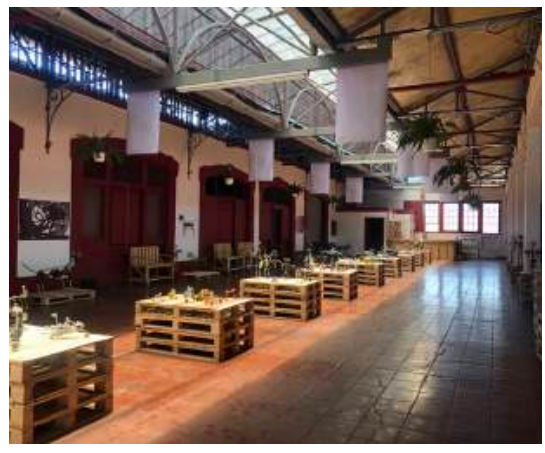

Figura 20. Exposición artística en interior de Antiguas Oficinas de UFC.

Fuente: Elaboración propia con base en el trabajo de campo (05/05/2019).

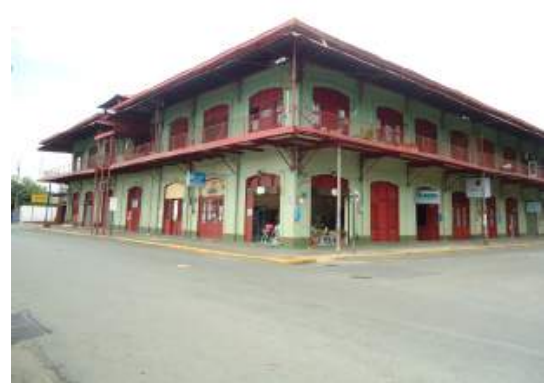

Figura 19. Antiguas Oficinas de la UFC.

Fuente: Elaboración propia con base en el trabajo de campo (11/10/2011).

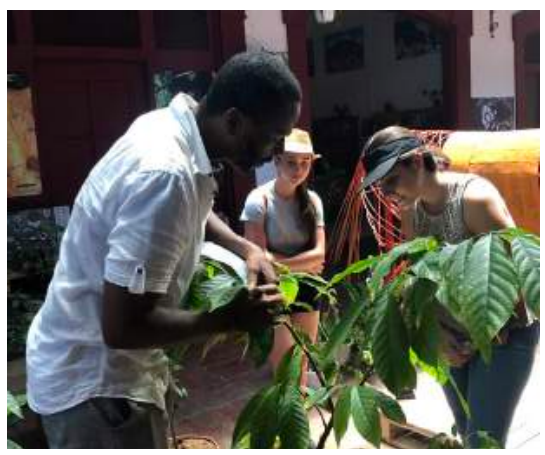

Figura 21. Interior de Antiguas Oficinas de UFC en donde se explican algunas características de la planta de cacao.

Fuente: Elaboración propia con base en el trabajo de campo (05/05/2019).

El edificio de los Almacenes, de una sola planta, posee un techo inclinado muy alto con dos linternillas. Ambos edificios presentan un gran alero que protege la acera del calor y la lluvia (figura 19). A pesar de presentar una menor integración climática, la Pensión Costa Rica (figuras 22 a 24) y el edificio de Correos y Telégrafos (figuras 25 y 26) son grandes exponentes de la arquitectura neoclásica. 
En las imágenes se puede apreciar el cambio que sufrió la senda en donde se ubica la Pensión Costa Rica. Primeramente estuvo destinada a carruajes y peatones (figura 22) y contaba con una importante dinámica social y económica en donde se observan personajes de diferentes edades y clases sociales. Llama la atención que la rotulación de los comercios se presenta tanto en inglés como en español evidenciando la multiculturalidad. Posteriormente esta calle se pavimentó hasta volver a peatonalizarse (figura 23 y 24). Otro edificio con importantes cualidades urbanísticas es el Pasaje Cristal, construido para albergar locales comerciales. Su configuración permite la circulación de los usuarios por la acera, ya que está protegida por la prolongación del alero apoyado por columnas metálicas, y posee una circulación interna peatonal, cubierta por una lámina transparente (figura 27 a 29).

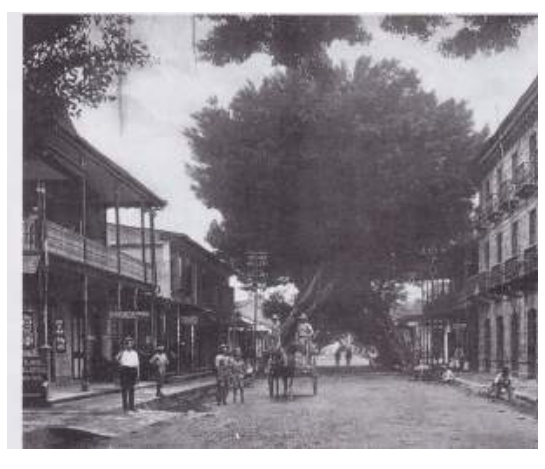

Figura 22. Fotografía histórica de una calle en Limón. A la derecha se observa la Pensión Costa Rica (De la Cruz, 2010, p. 86).

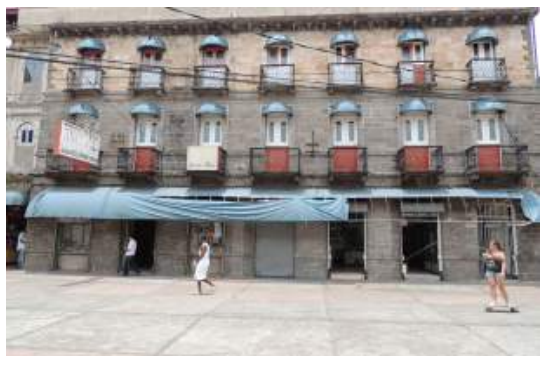

Figura 24. Pensión Costa Rica.

Fuente: Elaboración propia con base en el trabajo de campo (07/09/2012)

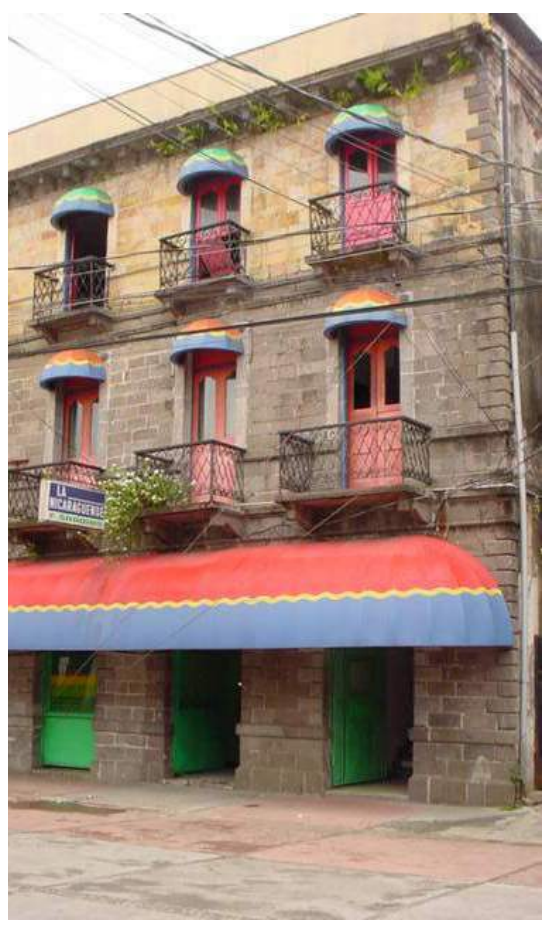

Figura 23. Pensión Costa Rica.

Fuente: Elaboración propia con base en el trabajo de campo (2002). 


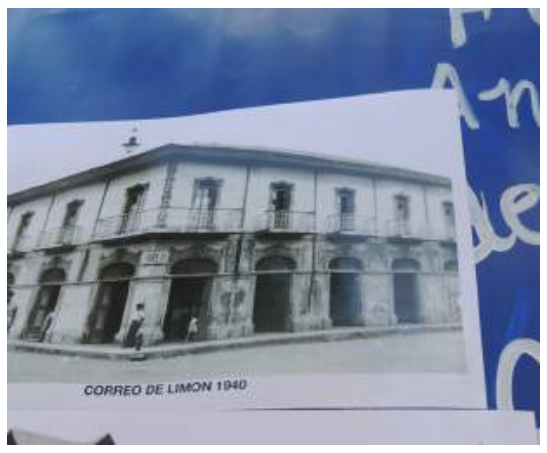

Figura 25. Fotografía de 1940 del Edificio de Correos. Fuente: Elaboración propia con base en el trabajo de campo (12/10/2013).

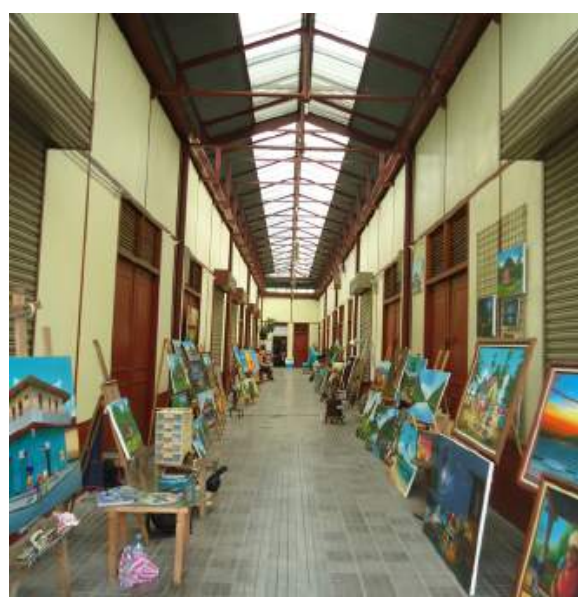

Figura 27. Pasaje Cristal.

Fuente: Elaboración propia con base en el trabajo de campo (11/10/2011).

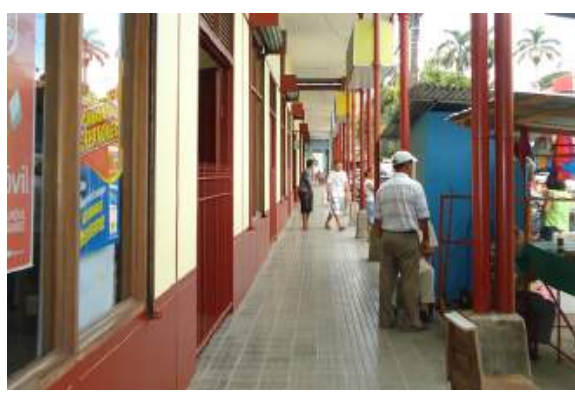

Figura 28. Pasaje Cristal.

Fuente: Elaboración propia con base en el trabajo de campo (11/10/2011).

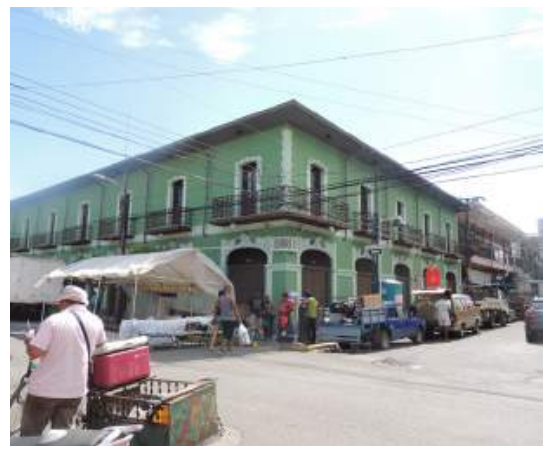

Figura 26. Edificio de Correos.

Fuente: Elaboración propia con base en el trabajo de campo (12/10/2013).

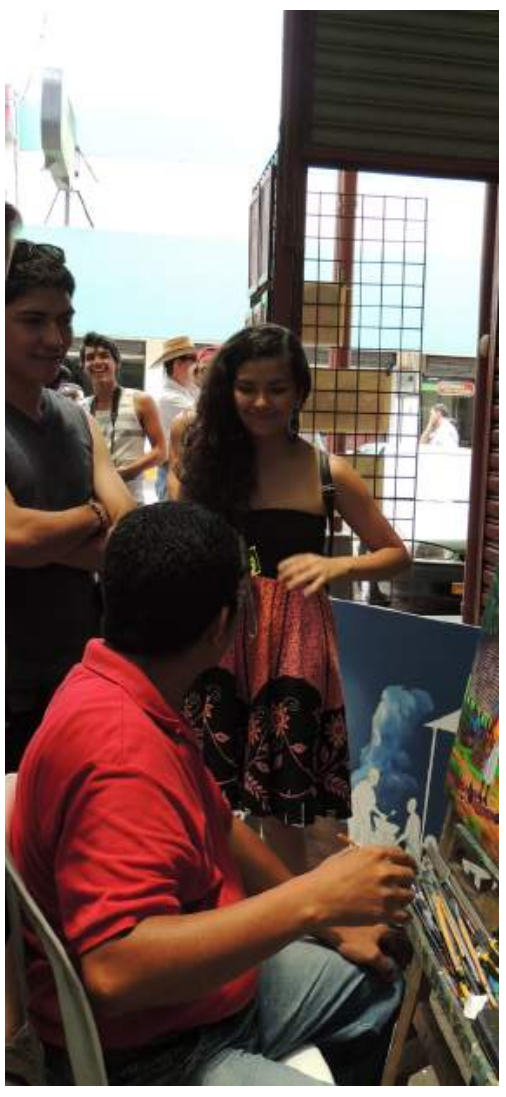

Figura 29. Pasaje Cristal.

Fuente: Elaboración propia con base en el trabajo de campo (07/09/2012). 
El Edificio de uso mixto de la Familia Ingianna Rosito (figuras 30 y 31), presenta un pasaje peatonal y su ubicación junto al Pasaje Cristal ayuda a que se conforme un gran paso protegido. La relación con el entorno es bastante obvia, pues presenta un corredor en la parte de abajo de gran altura y un balcón en la parte de arriba, así como pendientes muy pronunciadas que definen su influencia caribeña. Es muy interesante constatar que varias de las construcciones de este periodo (números 5, 6, 7, 8 y 9 en el mapa de la figura 2 y tabla 1) se agrupan en la Avenida 2, conformando una experiencia sensorial y un recorrido serial bastante agradable.

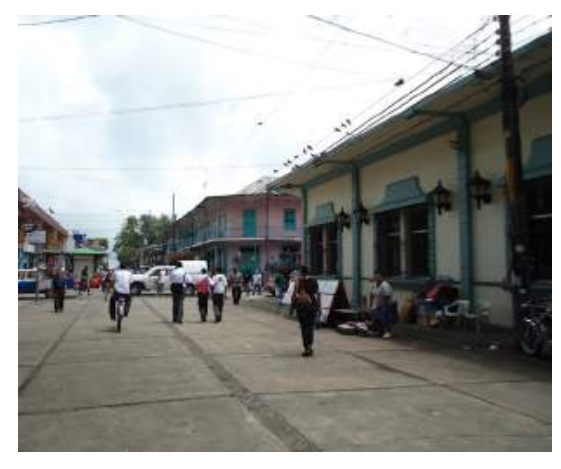

Figura 30. Edificio de la Familia Ingianna Rosito. Fuente: Elaboración propia con base en el trabajo de campo (28/02/2011).

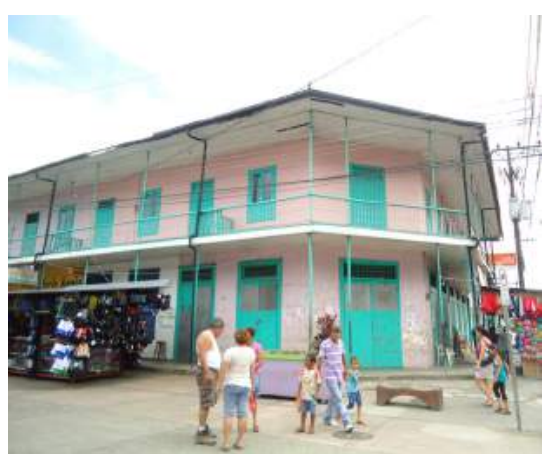

Figura 31. Edificio de la Familia Ingianna Rosito. Fuente: Elaboración propia con base en el trabajo de campo (11/10/2011).

Uno de los edificios más simbólicos y emblemáticos de la Ciudad fue el Black Star Line, construido en 1922, como sede del Movimiento Universal para el Mejoramiento del Negro (UNIA) que recuerda la herencia de Marcus Garvey, defensor de los derechos del negro (Zamora, 2012). Responde al sueño de muchos afrodescendientes de la época de movilizarse a África por medio de barcos con el mismo nombre del inmueble. 


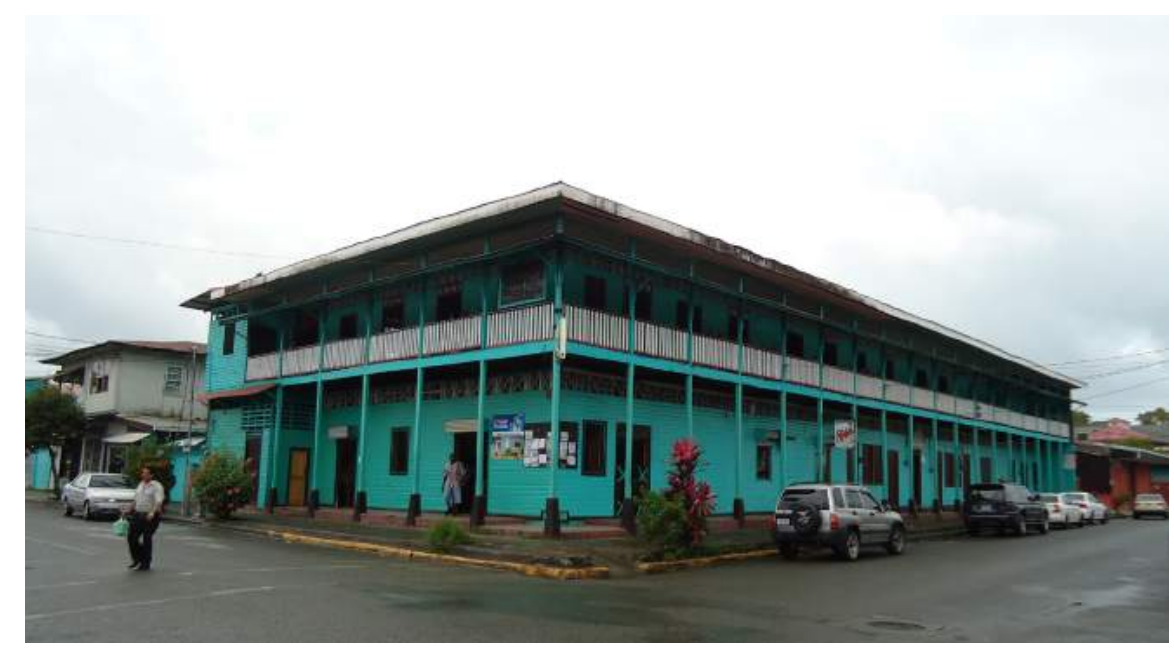

Figura 32. Edificio Black Star Line.

Fuente: Elaboración propia con base en el trabajo de campo (28/02/2011).

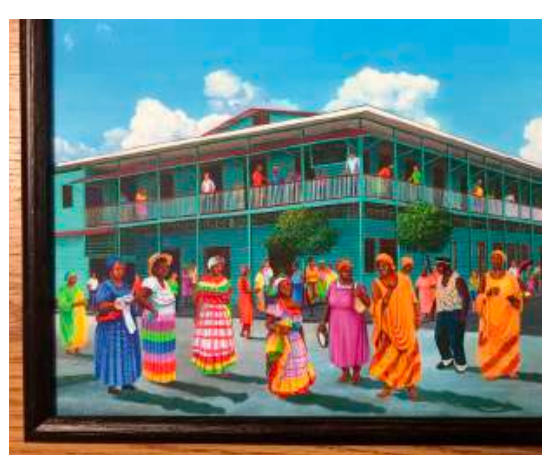

Figura 33. Fotografía de pintura de Cabraca.

Fuente: Elaboración propia con base en el trabajo de campo (08/03/2014).

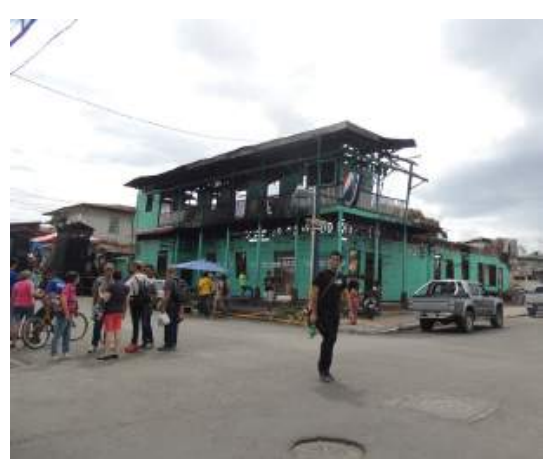

Figura 34. Edificio Black Star Line posteriormente destruido a causa de un incendio.

Fuente: Elaboración propia con base en el Figura de campo (14/05/2016).

Este edificio, consumido por el fuego en el 2016 (figura 34), conformaba un nodo cultural muy importante pues albergaba en su planta alta el Liberty Hall, en donde se realizaban todo tipo de actividades culturales como la celebración de 15 años de mujeres adolescentes, hasta bodas y reuniones políticas. Contaba con un pequeño escenario para albergar grupos musicales u oradores, un gran salón y balcones. Además, su posición esquinera y su gran permeabilidad hacia el exterior con balcones arriba y corredor abajo; su tipología caribeña y su llamativo color verde, le otorgaban 
una gran presencia en el entramado urbano. El diseño del Black Star Line se amolda convenientemente al clima, gracias a su materialidad en madera, la importante altura de la primera planta, parasoles en la segunda planta y fuertes pendientes en la cubierta (figura 32). El artista popular Cabraca recrea el edificio (figura 33), acompañado de diferentes personajes en su mayoría mujeres negras con coloridos atuendos fortaleciendo la imagen de negritud y extroversión de los caribeños.

Otro inmueble esquinero de la época fue el edificio de dos pisos denominado el hotel Cariari. Comparte algunas características de la arquitectura caribeña con el Black Star Line como los balcones y corredores, y la protección del primer nivel. Sin embargo en este caso, los materiales principales son ladrillo y estructura de concreto armado. Además, presenta una marcada influencia europea, con columnas que tienen decoraciones de influencia corintia y balaustradas latinas (imágenes 35 y 36).

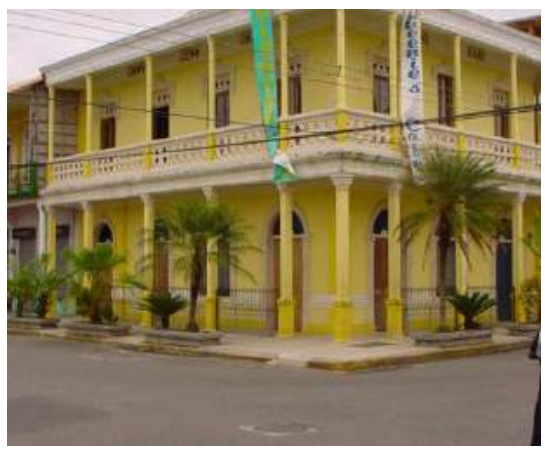

Figura 35. Hotel Cariari.

Fuente: Elaboración propia con base en el trabajo de campo (2002).

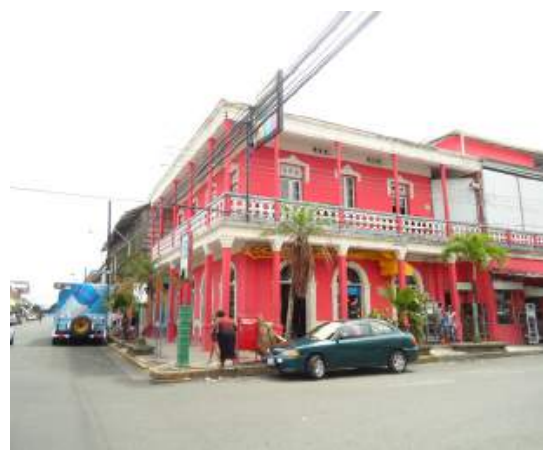

Figura 36. Hotel Cariari.

Fuente: Elaboración propia con base en el trabajo de campo (11/10/2011).

Entendiendo el patrimonio como la producción de una significación de un "objeto", en nuestro caso el Centro Histórico de Puerto Limón, para uno o varios grupos sociales, en un momento dado, que contribuye a definir una identidad colectiva. Es importante destacar que en la primera década del siglo XX se da una concentración urbana de negros en Puerto Limón. Paralelamente, las élites políticas del Valle Central estaban construyendo su imaginario de 
identidad muy centrado en una etnicidad blanca. Para Quince Duncan, los afrocostarricenses limonenses desarrollaron su cultura casi completamente al margen del Estado Nacional, construyendo formas de vida y tradiciones, más ligadas con su país de origen. Como consecuencia se creó el imaginario que tienen los costarricenses de Limón como sinónimo de negro. Se establecieron diferentes religiones, sistema escolar, en donde se utilizaba material didáctico traído de Jamaica y de Londres (Jones, 2010a).

Para Gómez Vargas (2010), la colonización multiétnica transformó una región prácticamente despoblada con el fenómeno de la inmigración que propició un complejo mosaico de culturas que cambiaría los paradigmas culturales de identificación del país (p.19). Para esta autora la presencia de inmigrantes afrocaribeños provocó una completa transformación cultural que abarcaba desde lo cotidiano como la vestimenta y las tradiciones culinarias hasta, paradigmas religiosos y filosóficos (p.20). En este contexto, se construyeron nuevos significados y expresiones culturales: se creó el inglés criollo limonense hablado cotidianamente, pero rechazado y sustituido por el inglés estándar en las escuelas y la iglesia.

Con la música calipso, el limonense descubrió una forma de proteger su historia y su identidad. Gracias a la creación de nuevas letras, los afrodescendientes encontraron una forma propia de mirarse y mirar el mundo y de narrar sus dramas con humor. El calipso se hizo canción del pueblo negro y los calypsonians sus representantes.

Por otro lado, para reforzar este aislamiento multicultural, al decaer la United Fruit Company y trasladarse al Pacífico, el gobierno intentó prohibir el paso de los negros hacia San José y aunque según Quince Duncan, nunca se dio esta ley, el mito fue más fuerte que la legalidad (Jones, 2010a). La ciudad de Turrialba se convirtió en la frontera imaginada que alejaba esta nueva etnia del interior del país. 
3. La "apertura" de Puerto Limón y las luchas sociales (19381970)

Según Woodbridge (2003) y Viales (1998), el auge económico de Puerto Limón decayó en 1938 con el traslado de la compañía bananera al Pacífico Sur. "La ciudad se paralizó por más de veinte años, periodo en el que cesa el desarrollo urbano planificado y se inicia el deterioro urbano que todavía persiste" (Woodbridge, 2003, p.137). "Hacia finales de la década de los cuarenta, comienza para Limón un periodo sombrío de gradual pauperización" (Duncan, 2005, p.122). Los negros de la segunda generación fueron personas sin patria, pues ni los países de sus padres ni Costa Rica les otorgaban la nacionalidad (Duncan, 2005, p.146). Se dan entonces, importantes transformaciones desde el punto de vista económico, social y político. Al estar recluidos y contar con sus propias reglas, los afrodescendientes fueron víctimas de abusos por parte de las bananeras que provocaron grandes huelgas en los años 30 del siglo XX. De ahí que esta problemática social se abre al resto del país naciendo la literatura de denuncia social. Las novelas Bananos y hombres, de Carmen Lyra, Mamita Yunai de Carlos Luis Fallas y Puerto Limón de Joaquín Gutiérrez, denunciaron la situación precaria que vivían los trabajadores de la United Fruit Company (Jones, 2010c). De esta forma se comienza a construir una consciencia social que va a dar cabida a la crisis del Estado y del discurso Liberal.

Después delavictoriade JoséFigueresFerrer, traslaguerradel 48 enese paíscentroamericano, comenzó el proyecto de nacionalización de la región. El presidente visitó Puerto Limón dando un discurso en inglés, intentando "integrar" a la comunidad afrocostarricense por primera vez en la vida política (Duncan, 2005, p.148). En 1949 se derogó la ley (imaginada) que dividía a Limón del resto del país. Además, se pasó una legislación para naturalizar a los negros de Limón y darles su derecho al voto. En los años 50 y 60, el gobierno de Costa Rica como norma de Estado, tomó la decisión de cerrar las 
escuelas de habla inglesa en Limón (Jones, 2010b). Se inventaron muchas maneras para descalificar el inglés criollo limonense, hasta describiéndolo como lengua de menor categoría. Se implantaron nuevos medios de homogenización, imponiendo el idioma español, la religión católica y como menciona Duncan, aunque no fue posible blanquear la piel de los limonenses, se logró blanquear su mente (Jones, 2010b).

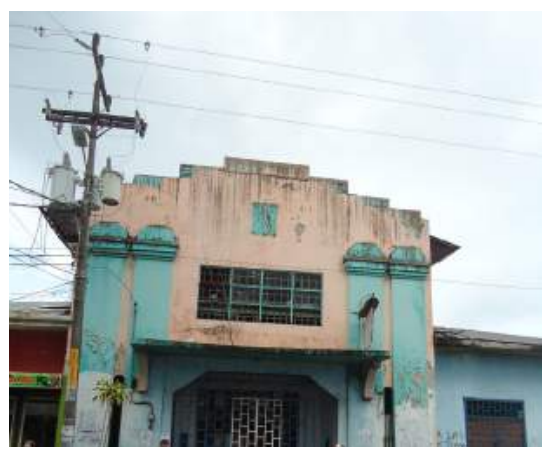

Figura 37. Casa de la Cultura.

Fuente: Elaboración propia con base en el trabajo de campo $(28 / 02 / 2011)$.

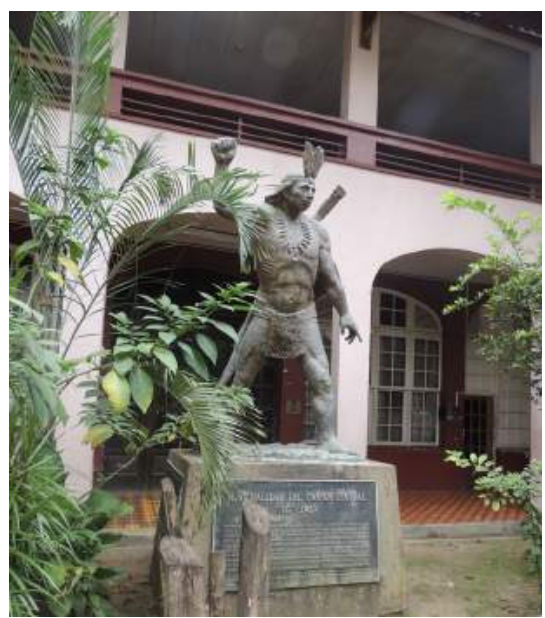

Figura 39. Patio de la Municipalidad de Limón. Fuente: Elaboración propia con base en el trabajo de campo (17/10/2015).

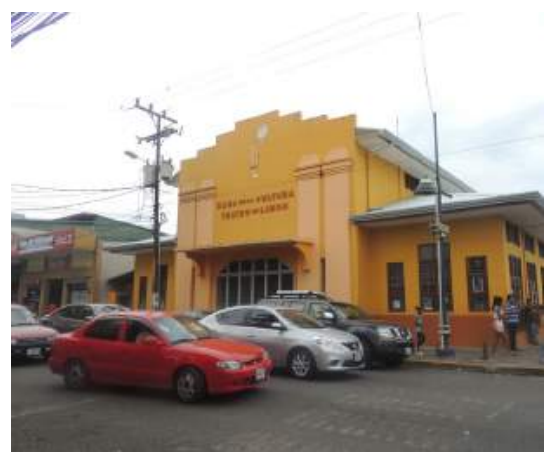

Figura 38. Casa de la Cultura. Elaboración propia con base en el trabajo de campo (17/10/2015).

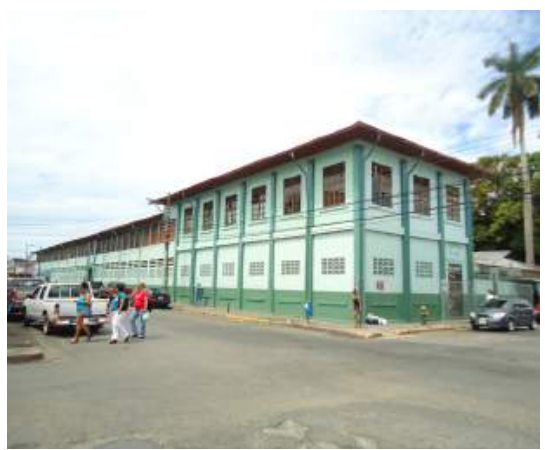

Figura 40. Escuela General Tomás Guardia.

Fuente: Elaboración propia con base en el trabajo de campo (11/10/2011). 
En la década de los 60 se dio un crecimiento en la actividad portuaria, lo que motivó una nueva migración. Sin embargo, con esto crecieron los barrios marginales y se dio una tendencia a subdividir la manzana, perdiéndose los patios limonenses (figura 10). Además, se demolieron gran número de edificaciones tradicionales y se construyeron inmuebles traídos del Valle Central, que no respetaban la configuración urbana, el clima, ni la apertura al contexto presentada por las edificaciones tradicionales. Se comenzaron a marginalizar los diferentes patrimonios relacionados con la identidad negra o diversa. No obstante, nacieron otras tradiciones como el carnaval limonense, fundados por Alfred King en 1949 (Arley, 2013). Los Carnavales propician la apropiación de la ciudad reforzando el carácter de identidad. Para esta época también se construyeron nuevos edificios hoy declarados patrimonio, con un estilo más internacional y menos local, como lo son la Casa de la Cultura (1938, figuras 37 y 38), de estilo art decó, el Mercado Municipal, la Municipalidad de Limón, de estilo neocolonial o neohispánico (1942, figura 39) y la Escuela General Tomás Guardia (1940-1948, figura 40).

4.Exaltación y distorsión de la multiculturalidad. Contradicciones y retos (1970-2019)

Este último periodo se ha caracterizado por la exaltación de los intereses comerciales, turísticos y políticos; las contradicciones discursivas; la falta de planificación; la patrimonialización formal del estado de algunos inmuebles y el debilitamiento de lo local en pro de los procesos de globalización, propios de la época. En 1987 la construcción de la carretera Limón-San José, ruta 32, potenció el cierre del INCOFER en 1995. El desplazamiento del ferrocarril conllevó a la pérdida de importantes formas de vida y tradiciones, como por ejemplo la venta de comidas tradicionales a lo largo del trayecto y la imagen urbana histórica basada en este medio de transporte. 
Por otro lado, el carnaval limonense hasta los años 70, fue un verdadero espacio de expresión del pueblo caribeño. Para Rogelio Williams, director de la comparsa "Super Stars", el recorrido que realizan Los Carnavales ha sido trascendental, saliendo de la playa los Baños, pasando luego por el Hotel Puerto y siguiendo su trayectoria hacia el Estadio de Béisbol, para culminar con emoción en el Parque Vargas (Ramírez, 2008) (figura 2). Dicho recorrido se encuentra dentro de nuestra zona de estudio, reforzando el valor social que la población le ha otorgado a la ciudad.

En las décadas de 1980 a 1990, cuando la municipalidad empezó a administrar la organización de Los Carnavales, esta tradición se comenzó a vislumbrar como un negocio, destinado a vender una imagen distorsionada de la cultura afrolimonense. Desde entonces hasta la actualidad, el evento se orienta más hacia el consumo masivo y menos para la creación y el encuentro, reemplazándose, por ejemplo, el calipso por música comercial y en donde incluso algunas comparsas solicitan un pago para su participación.

Para Prats, (1998) el patrimonio también puede gestarse desde la construcción política; afirmando que "sin poder, no existe el patrimonio" (p. 69), donde en la mayoría de los casos existe una intención política y de poder a la hora de construir patrimonios desde el gobierno. En este periodo, se promovieron decretos para las declaratorias de los veinte edificios patrimoniales mencionados al inicio de este artículo, comenzando por el de Correos y Telégrafos, en 1981, hasta la Casa Episcopal en el 2013.

En el 2012, adicionalmente, se declaró el Calipso Limonense como expresión del patrimonio inmaterial afrodescendiente. Paradójicamente, esta patrimonialización se ha debido más que todo al debilitamiento y pérdida de valor de los mismos objetos patrimoniales, argumentando la necesidad de rescatar lo que alguna vez estuvo en plena vitalidad. En 1995, ICOMOS, realizó un 
primer estudio sobre el Centro Histórico de Puerto Limón. Esta entidad y el Ministerio de Cultura se han aliado para generar estudios y proyectos como la peatonalización de la Avenida Segunda. Además, en los últimos años se han realizado trabajos de restauración de la Capitanía del Puerto, el Edificio de Correos y Telégrafos, y la Casa de la Cultura.

A pesar de todos estos esfuerzos, la Ciudad presenta un nivel de deterioro importante y se encuentra inmersa en contradicciones y en procesos políticos inconclusos que generan mucha incredulidad entre sus habitantes. Un ejemplo de esto es el proyecto de Limón Ciudad Puerto, que contó con un importante financiamiento del Banco Mundial, pero que tras su cierre en el 2014 , solo pudo concretar un avance del $35 \%$ de las obras y el $7 \%$ de la ejecución presupuestaria. Este proyecto fue parte de la campaña política del expresidente Óscar Arias Sánchez (2006-2010), bajo el lema "Limón brillará como una perla". Después de dos gobiernos de Liberación Nacional, la falta de planificación, interés y trabajo entre entidades públicas hizo que el proyecto decayera. Se aspiraba a la revitalización del Centro Histórico de Limón y áreas conexas para su desarrollo como polo turístico, ya que pretendía que el turista de cruceros y nacional permaneciera más tiempo en el territorio de estudio, reactivando la economía local.

Asimismo, en el año 2015, la mala administración de fondos le pasa la factura a Los Carnavales de Limón, en donde se decide posponerlos pues según las autoridades generaban pérdidas monetarias. En algunos años el carnaval fue suspendido por el Ministerio de Salud Pública de Costa Rica debido a la alta incidencia de enfermedades como el dengue y otras. Sin embargo, para muchos, el privarse de esa tradición es sinónimo de despojarse de un espacio efímero de desahogo y liberación así como de un medio de expresión y una plataforma cultural para la ciudad. 
Por otro lado, algunos jerarcas han solicitado la construcción de un campo ferial. No obstante, la ciudad, sus calles y el espacio público han sido el principal receptor de esta actividad. La consolidación de un espacio externo a este contexto podría desvalorizar la riqueza sensorial del recorrido antes mencionado.

A pesar de las declaratorias y promesas políticas, se percibe todavía un importante sentimiento de olvido y desinterés desde los gobiernos central y local. Por negligencia y descuido en el mantenimiento, el Black Star Line se incendió en abril de 2016. Este edificio, como se explicó anteriormente, poseía un gran arraigo y valor simbólico para la comunidad afrodescendiente; y el Liberty Hall fue utilizado para diferentes eventos festivos en los últimos años (figuras 41). A pesar de ser una reconstrucción de los noventas, la comunidad se ha manifestado para gestar su reconstrucción, con el lema "Rebuilt a dream" (figura 42).

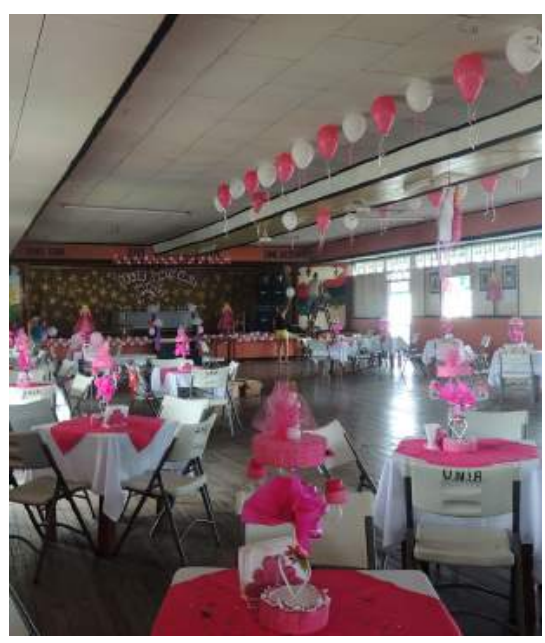

Figura 41. Liberty Hall decorado para evento social. Fuente: Elaboración propia con base en el trabajo de campo (22/09/2012).

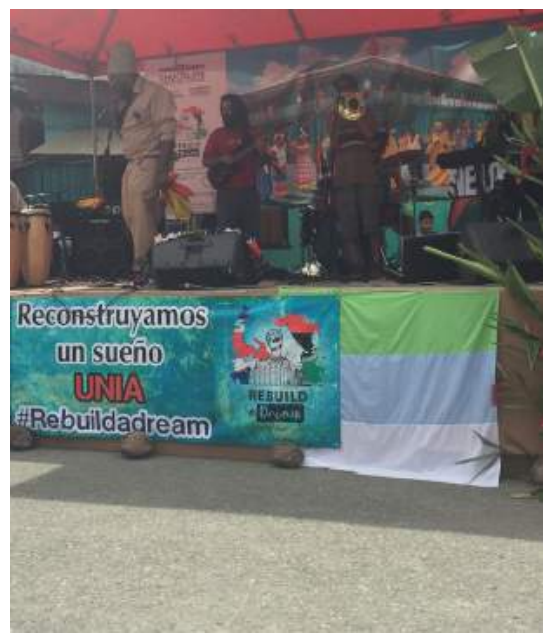

Figura 42. Concierto en las afueras del Black Star Line para recaudar fondos para la reconstrucción del inmueble.

Fuente: Elaboración propia con base en el trabajo de campo (14/05/2012). 


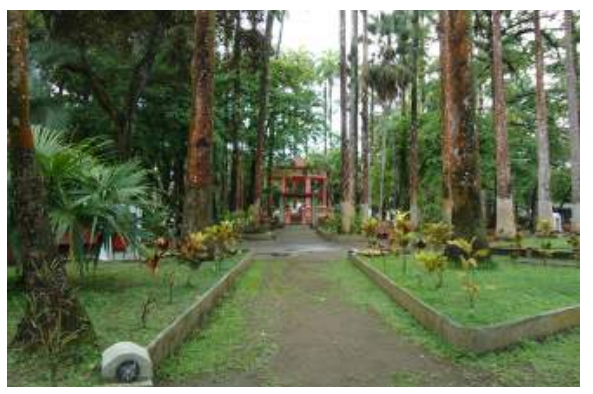

Figura 43. Parque Vargas.

Fuente: Elaboración propia con base en el trabajo de campo (28/02/2011).

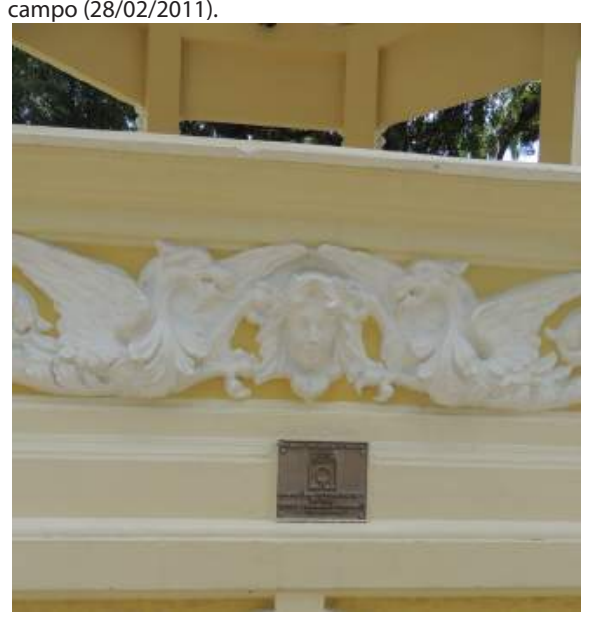

Figura 44. Parque Vargas.

Fuente: Elaboración propia con base en el trabajo de campo (08/03/2014).

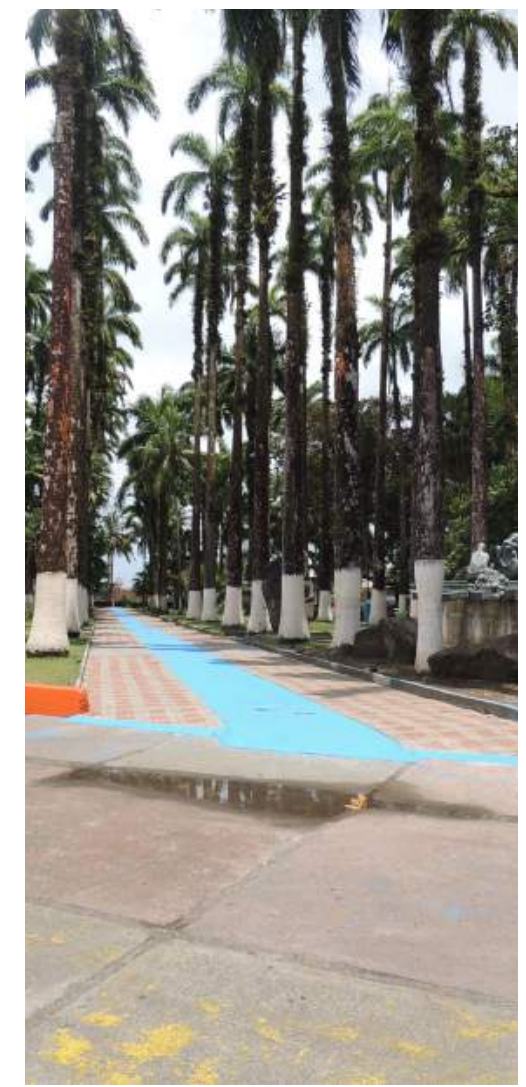

Figura 45. Parque Vargas.

Fuente: Elaboración propia con base en el trabajo de campo (14/05/2016).

Por otro lado, las figuras 43,44 y 45 nos muestran los cambios en cuanto a materiales de sendas y restauraciones recientes que se han desarrollado en el Parque Vargas, testigo del interés que aún existe en la conformación de este espacio público. No obstante se debe tener un cuidado especial en no estandarizar los espacios patrimoniales, y borrar la huella que le dan su particularidad. Por ejemplo, se han incluido letras corpóreas, como parte del "marketing" de la ciudad, siendo este tipo de íconos objetos globalizantes de las principales ciudades del mundo (figura 46). A pesar de esta tendencia a la estandarización aún persisten 
tradiciones en el parque como la venta de "patty" y "plantinta" (figura 48), y se han realizado esculturas que recuerdan la multietnicidad de la zona (figura 49). Por otro lado el parque concentra diversidad de fauna que apoya los sentidos sensoriales y visuales en el recorrido (figura 47).

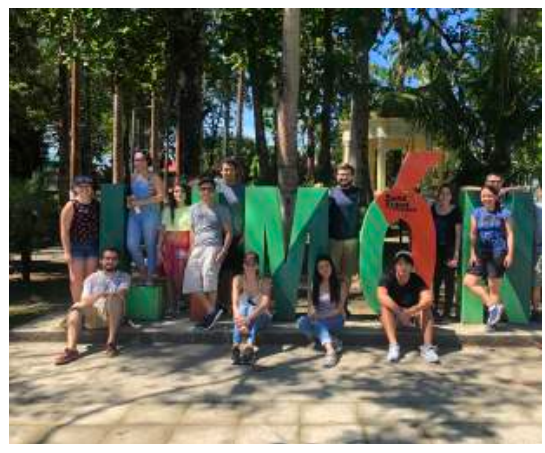

Figura 46. Letras corpóreas.

Fuente: Elaboración propia con base en el trabajo de campo (07/10/2018).

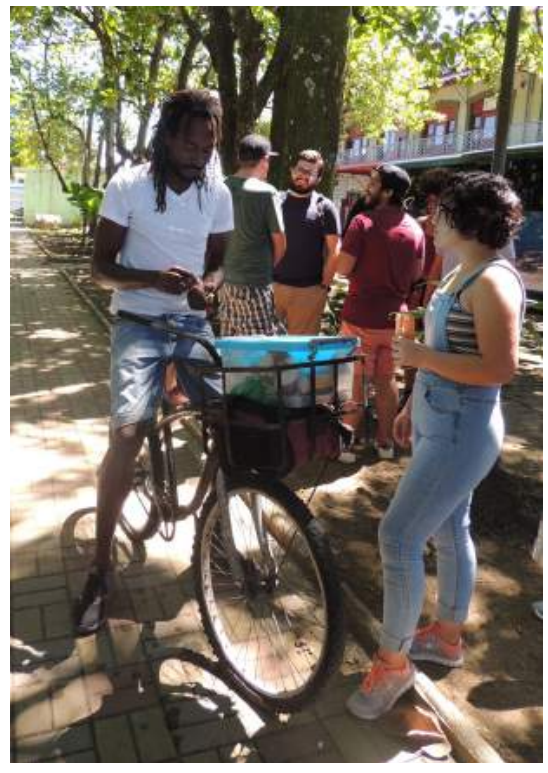

Figura 48. Vendedor de patty y plantinta. Fuente: Elaboración propia con base en el trabajo de campo (07/10/2018).

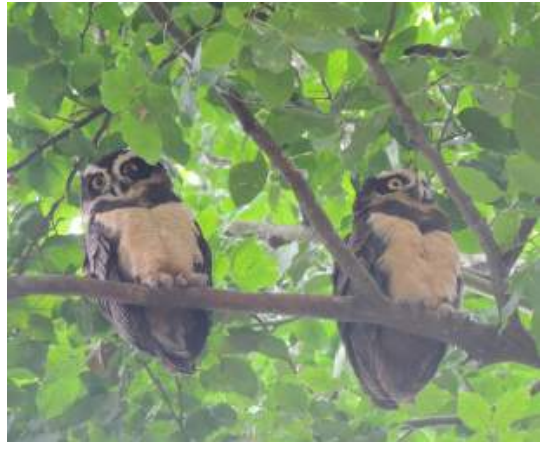

Figura 47. Búhos en Parque Vargas.

Fuente: Elaboración propia con base en el trabajo de campo (04/05/2013).

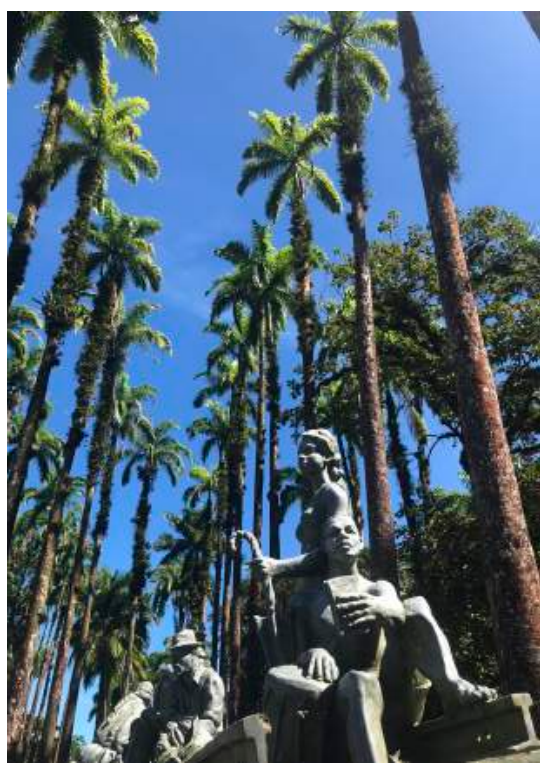

Figura 49. Escultura en Parque Vargas.

Fuente: Elaboración propia con base en el trabajo de campo (07/10/2018). 
Otro edificio que actualmente preserva el uso para el cual fue erigido es el Pasaje Cristal, en donde existen diferentes negocios y se reúnen artesanos a realizar pinturas donde el tema principal son los edificios patrimoniales y la gente del lugar en diferentes épocas históricas. En la figura 18 vemos uno de las pinturas en donde se muestra el edificio de la "United Fruit Company", cuando el ferrocarril estaba en funcionamiento. Este edificio de las Antiguas Oficinas de la UFC, presenta un cambio de uso prometedor, en donde se ha incorporado una galería de arte (figura 20 y 21), venta de productos comestibles con base a productos tradicionales como el cacao, un vivero de especies de la zona y espacios culturales donde se promueve el calipso (figuras 50 y 51 ).

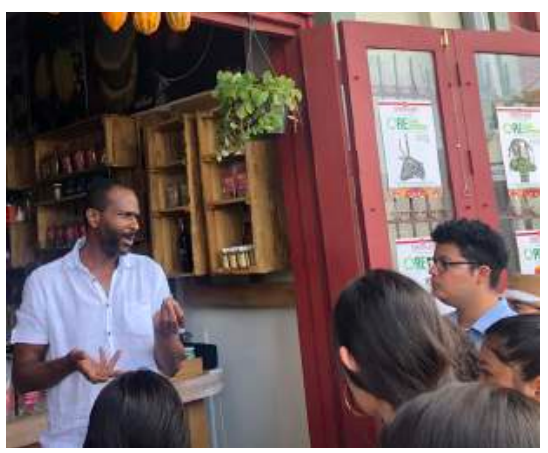

Figura 50. George Grant, director "G\&E Chocolate Adventure Company", explicando proceso de elaboración de cacao en Cacao y Chocolate en Antiguas Oficinas de UFC.

Fuente: Elaboración propia con base en el trabajo de campo (05/05/2019).

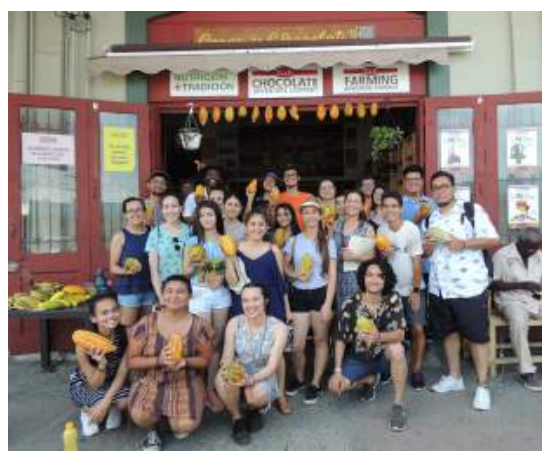

Figura 51. Antiguas Oficinas de UFC. Grupo universitario de Seminario de Realidad Nacional de la UCR, con George Grant, y el cantante Johnny Dixon, uno de los artistas más destacados de la provincia.

Fuente: Elaboración propia con base en el trabajo de campo (05/05/2019).

Finalmente, la falta de planificación y proyectos inconclusos preocupan a las comunidades. Se vislumbran 2 grandes proyectos que podrían generar importantes repercusiones en la Zona: el proyecto de APM Terminals Moín y la ampliación de la carretera 32 a cuatro carriles por parte de la empresa China Harbour Engineering Company (CHEC) proyectada para el 2019. 


\section{RESULTADOS, ANÁLISIS Y DISCUSIÓN}

Para Prats (1998), los criterios constituyentes para la patrimonialización son: "la naturaleza, la historia y la genialidad" (p.63). Para Gómez Macedo (2010) el "patrimonio es una entidad viva, donde coexisten diferentes tipos de valores que están interactuando unos con otros" (p.4). Podemos afirmar que el área de estudio posee valores de diferentes tipos que han sido transformados a lo largo del tiempo por diferentes grupos sociales. Se argumentará por qué la zona estudiada cuenta con los valores comentados a continuación.

\section{VALOR HISTÓRICO}

Como hemos visto, el $\mathrm{CH}$ de Puerto Limón ha sufrido importantes transformaciones sociales, culturales, políticas, económicas y urbanas a lo largo de la historia. Se delimitaron 4 diferentes periodos de transformaciones que se dividieron de la siguiente manera: resistencias y autonomía frente al poder hegemónico español (1502-1852); la construcción formal de Puerto Limón, consolidación de una nueva cultura multiétnica al margen de "Costa Rica" (1852-1938), en donde la ciudad experimentó un auge económico debido a tres actividades: la construcción del ferrocarril, la actividad portuaria y el enclave bananero, creándose el Puerto más importante del país (Viales, 1998) ; la "apertura" de Puerto Limón y las luchas sociales (1938-1970) y; por último, se define una época de contradicciones y retos de exaltación y distorsión de la multiculturalidad (1970-2019). En el segundo periodo podemos considerar que se dio un primer proceso de patrimonialización de sus habitantes gracias a la ideación y construcción de una nueva ciudad que exaltó la arquitectura caribeña y diferentes espacios sociales y tradiciones intangibles arraigados a la cultura afrocaribeña pero al margen del imaginario "costarricense". En el tercer periodo, por el contrario, con la apertura de la región al resto del país se vivió un proceso de desvalorización de lo que había sido patrimonializado por la población afrocaribeña como el inglés criollo y la arquitectura caribeña, para introducir estilos 
arquitectónicos de tendencias internacionales. Finalmente, en el cuarto periodo se patrimonializa institucionalmente una serie de bienes tangibles e intangibles de diferentes épocas con una intención turística y económica por parte del gobierno.

\section{VALOR SOCIAL Y SIMBÓLICO}

A lo largo de las capas históricas analizadas se evidenciaron la diversidad de actores sociales que le han dado significado tanto al centro histórico como a las tradiciones que envuelven sus edificios. Para la construcción del ferrocarril al Atlántico vinieron chinos e italianos, pero la obra no hubiese sido posible sin la ayuda de los negros de Jamaica. Estos últimos se quedaron en Limón para trabajar en la industria bananera. Fue en ese momento que se construye la identidad del negro limonense, consolidándose un idioma: el inglés criollo limonense, creándose una música propia: el calipso limonense y costumbres culinarias particulares. Las injusticias sociales que vivieron los negros potenciaron, además ,huelgas y protestas en donde el jamaiquino Marcus Garvey tuvo gran protagonismo, y participó en la construcción simbólica del edificio Black Star Line y de la misma ciudad histórica. Por otro lado, construcciones como el Parque Vargas, el Estadio Big Boy y el Tajamar han apoyado la vida entre los edificios y la cohesión social. Además, la creación de "los patios limonenses" en medio de las manzanas, las casas de dos pisos donde vivían varias familias y la protección de las aceras con aleros han provocado una vida comunal de mayor intensidad que en otras ciudades del país (Woodbridge, 2003).

\section{VALORES ESTÉTICOS Y PAISAJÍSTICOS}

El paisaje costero, la apertura hacia el mar Caribe, la isla Quiribrí como punto focal, el ritmo de las palmas reales, la exuberancia en cuanto a vegetación del parque Vargas, la sinuosidad del malecón, el sonido y la brisa proveniente del mar, los cantos de los pájaros, 
son sin duda valores paisajísticos y estéticos que presenta la zona de estudio. Por otro lado, la consolidación de una arquitectura caribeña, pilotes, grandes alturas, aleros de protección y la costumbre de construir casas en grupo apoyaron la percepción de unidad del conjunto arquitectónico.

\section{VALOR CIENTÍFICO}

Para Prats (1998), el conocimiento de la diversidad cultural, referido al de los logros científicos y artísticos más singulares, representa el verdadero patrimonio que se puede conservar y transmitir. Nuevos métodos constructivos, materiales y avances en infraestructura son algunos ejemplos de los conocimientos innovadores que se generaron bajo la conformación de la ciudad. Se desarrolló, además, una nueva tipología: la arquitectura caribeña costarricense que se adaptó al calor intenso y las fuertes lluvias de la zona y tuvo influencia de la arquitectura anglo-antillana. Desde el punto de vista de la planificación urbana, se creó el primer instrumento de ordenamiento público.

Además, se creó el Calipso limonense, declarado expresión del patrimonio inmaterial afrodescendiente en el 2012 por parte del Ministerio de Cultura y Juventud. Se generaron temas sociales y políticos, de carácter irónico y burlesco en donde el contexto de los acontecimientos era el mismo Centro Histórico. Asimismo, se creó una nueva variedad criollizada del inglés conocida como el inglés criollo limonense. 


\section{CONCLUSIONES}

En los últimos años se han patrimonalizado cascos históricos latinoamericanos, convirtiéndose en algunos casos, en Patrimonio Mundial de la Humanidad, como son la ciudad de Cartagena, La Habana, Lima, entre otras. Se ha tendido a revalorizar espacios históricos dotando de mobiliario, equipamiento urbano e iluminación a los espacios entre los edificios. Sin embargo, se ha apostado a empresas globalizadas que más que preservar, van transformando la ciudad y estandarizándola, desde una visión internacional.

Para Cabrera (2010), el proceso de patrimonialización en varias ciudades latinoamericanas ha potenciado la desigualdad y fragmentación, en el sentido que se genera un alejamiento de los sectores sociales más frágiles, que antes de la patrimonialización de los objetos patrimoniales revalorizados, eran los usuarios $u$ ocupantes de estos sitios. Esto, genera una falta de reconocimiento de los sectores más vulnerables y un desapego a lo que en un inicio se valorizaba. Un ejemplo de esto es el fenómeno de gentrificación que desplaza la población original luego de la intervención de "un sitio a valorizar".

Se debería más bien pensar en un proceso de patrimonialización que sea socialmente inclusivo y participativo, para evitar la estandarización. En el caso de la Ciudad de Limón, se esperaría mantener el uso mixto que tuvo la mayoría de sus inmuebles para evitar el fenómeno de despoblamiento del centro que ya se dio en San José y se está dando en ese contexto. El turismo y las nuevas transformaciones sociales, podrían reproducir nuevos elementos patrimoniales. La restructuración y el mejoramiento de los espacios urbanos, involucrando la participación de los habitantes, lograría revelar las cualidades y contribuir al descubrimiento y la creación del nuevo patrimonio. 
Puerto Limón alberga un gran número de"objetos patrimoniales" tanto tangibles como intangibles que le han dado a la ciudad diferentes significados a lo largo del tiempo, constituyendo una de las fuentes más valiosas en la consolidación de su identidad. Algunos tramos, todavía mantienen cierta calidad ambiental tradicional del espacio público y de la arquitectura y han sido testimonio de fiestas y carnavales. Por formar parte del patrimonio histórico del Centro Histórico de Puerto Limón y por su gran adaptación al clima tropical, la arquitectura anglo caribeña de este puerto sugiere la importante necesidad de su re-valorización. Como lo vimos en los 4 procesos de transformación del sector estudiado, los actores han sido diversos, y la apertura del puerto a lo nacional ha traído consecuencias de discriminación y desvalorización de lo local.

Finalmente, el patrimonio cultural está en constante transformación y renovación y es el resultado de un proceso histórico y social concreto. El Centro Histórico de Limón ha tenido distintos significados a lo largo del proceso de construcción como patrimonio, es un ser inacabado que se va construyendo y transformando por sus habitantes. La sobrevivencia del inglés criollo, los carnavales, el calipso limonense, la conformación del espacio urbano, los patios limonenses y la arquitectura tradicional de la zona estudiada depende de la actitud política que tomen los mismos limonenses, ante su lengua ancestral, sus fiestas tradicionales y su visión de ciudad, así como de las construcciones políticas, económicas y sociales gestadas por los gobiernos centrales y locales. 


\section{BIBLIOGRAFÍA}

Arley, M. (2013). Carnavales en Limón: ¿El demonio rebelde o el festejo ser conquistados? Revista Herencia, 26 (1 y 2), p. 121-126.

Cabrera, C. (2010). Límites, posibilidades y paradojas en la construcción social de los procesos de patrimonialización urbana. El caso Buenos Aires. Recuperado de http:// naerus.net/web/sat/workshops/2010/pdf/PAPER_ cabrera_c.pdf

Chang Vargas, G. (2004). Patrimonio cultural, diversidad en nuestra creación y herencia. San José, Costa Rica. MCJD.

Centro de Conservación Patrimonio Cultural. (2016). Patrimonio.go.cr. Recuperado de http://www. patrimonio.go.cr

De la Cruz de Lemos, V. (2010). Historia general de Costa Rica. San José, C.R. Grupo Nación.

Davallon, J. (2006). Le don du patrimoine: une approche communicationnelle de la patrimonialisation. Coll. Communication, médiation et construits sociaux. Paris. Lavoisier, coll. Hermès Science.

Dormaels, M. (2011). Patrimonio, patrimonialización e identidad. Hacia una hermenéutica del patrimonio. Revista Herencia, 24 (1 y 2), p. 7-14.

Drouin, M. (2005). Le combat du patrimoine à Montréal (1973-2003). Coll. Patrimoine Urbain. Québec. Presses de L'Université du Québec.

Duncan Q. (2005). El negro antillano: inmigración y presencia. En Carlos Meléndez Chaverri (Ed.), El negro en Costa Rica. (pp.114-204) San José. C.R. Editorial Costa Rica.

Fonseca, E.; Alvarenga, P. y Solórzano, J. C. (2002). Costa Rica en el Siglo XVIII. San José, Costa Rica. EUCR.

Fonseca, E. y Barascout E. (1998). Historia de la Arquitectura Colonial. En E. Fonseca y J. E. Garnier. (Ed.), Historia de la Arquitectura en Costa Rica. (pp. 81-150) San José, Costa Rica. Fundación Museos del Banco Central de Costa Rica.
García Canclini, N. (1996). Imaginarios urbanos, 3 conferencias en Buenos Aires. México. Editorial Grijalbo.

Gómez Macedo, D. (2010). Los valores en el patrimonio arquitectónico. Ponencia $X$ Congreso Internacional Rehabilitación del Patrimonio Arquitectónico y Edificación. Chile. Centro Internacional para la Conservación del Patrimonio (CICOP).

Gómez Vargas, S. L. (2010) La música Gospel en Limón. San José, Costa Rica. Centro de Conservación Patrimonio Cultural.

Gutiérrez, A.; Jiménez, A.; y Martínez, L. C. (2013). Construcción geográfica de la provincia de Limón. Costa Rica, poder, cultura y territorio. Anuario CIEP, 4 (2), p. 228-245.

Gutiérrez, S. (1991). Arquitectura Caribeña. Colombia. Editorial Escal.

Jones, S.; Ramírez, D.; y Porras, I. (2010a). El negro en la literatura costarricense. En Porras, I. Identidades. San José: Programa de Producción de Materiales Audiovisuales, Universidad Estatal a Distancia.

Jones, S., Ramírez, D.; y Porras, I. (2010b). Inglés criollo limonense. En Porras, I. Identidades. San José: Programa de Producción de Materiales Audiovisuales, Universidad Estatal a Distancia.

Jones, S., Ramírez, D. y Porras, I. (2010c). La otra Carmen Lyra. En Porras, I. Identidades. San José: Programa de Producción de Materiales Audiovisuales, Universidad Estatal a Distancia.

López Garat, R. (1984). Características urbanas tradicionales Limón. Revista del Colegio de Ingenieros y Arquitectos, Habitar. 3 (15), p. 22.-31.

Meléndez Chaverri, C. (2005). El negro antillano: inmigración y presencia. En C. Meléndez Chaverri (Ed.), El negro en Costa Rica. (pp.73-111) San José. C.R. Editorial Costa Rica. 
Pérez Winter, C. V. (2017). Los procesos de patrimonialización y turistificación en la legitimación de paisajes desiguales / Heritage and tourism processes in the legitimization of unequal landscapes. Revista Sociedade \& Natureza, 29 (2), p. 195-208. doi: http:// dx.doi.org/10.14393/SN-v29n2-2017-

Prats, L. (1998). El concepto de patrimonio cultural, Política y Sociedad. Recuperado de http://antropologiasocial. org/contenidos/publicaciones/otautores/prats $\% 20$ el\%20concepto\%20de\%20patrimonio\%20cultural.pdf

Ramírez, V. (2008). Carnavales de Limón. Forjadores. San José: Producción de Canal 15, Universidad de Costa Rica.

Ruz, M. H. (1991) Melodías para el tigre. Pablo de Rebullida y los indios de la Talamanca. 1694-1709. Revista de Historia, (23), p. 59-105.

Sanou, O. y Quesada, F. (1998).Orden, progreso y civilización (1871-1914). En Elizabeth Fonseca y José Enrique Garnier. (Ed.), Historia de la Arquitectura en Costa Rica. (pp.81-150) San José, Costa Rica. Fundación Museos del Banco Central de Costa Rica.

Sanou Alfaro, O. (2010). Costa Rica. Guía de Arquitectura y Paisaje. San José-Sevilla. Editorial Junta de Andalucía. UNESCO. (2011). Ley de los Monumentos Nacionales y Locales. Recuperado de http://www.unesco.org/ culture/natlaws/media/pdf/cuba/cuba_ley2_spaorof. pdf

Viales, R. (1998). Limón después del enclave 1927-1950. San José, Costa Rica. Editorial de Universidad de Costa Rica.

Woodbridge Paris, R. (2003). Historia de la Arquitectura en Costa Rica. Cartago, Costa Rica. Editorial Tecnológico de Costa Rica.

Zamora Hernández, C. (2012). Limón, Cahuita y Puerto Viejo. San José, Costa Rica. Ministerio de Cultura y Juventud. Centro de Investigación y Conservación del Patrimonio Cultural, Imprenta Nacional. 